Cómo citar este trabajo: Bernabé-Crespo, M. B. (2021). Geographical analysis for conflict prevention: Moldova, focus of geopolitical tension. Boletín de la Asociación de Geógrafos Españoles, (90). https://doi.org/10.21138/bage.3094

\title{
Un análisis geográfico para prevenir el conflicto: Moldavia, foco de tensión geopolítica
}

Geographical analysis for conflict prevention:

Moldova, focus of geopolitical tension

\author{
Miguel Borja Bernabé-Crespo \\ miguelb.bernabe@uam.es \\ Departamento de Geografía \\ Universidad Autónoma de Madrid (España)
}

\section{Resumen}

El espacio exsoviético representa un área de influencia disputada y donde se desarrollan estrategias de desestabilización propias de la zona gris. El análisis de la distribución de etnias, lengua, indicadores económicos y geografía electoral puede servir como herramienta para identificar aquellas regiones netamente diferenciadas del resto y que puedan socavar su estatalidad. Moldavia constituye un buen ejemplo debido a la persistencia de un conflicto congelado (Transnistria), una región autónoma (Gagauzia) y una polarización política entre el proeuropeísmo y la alianza con Rusia. Los datos provienen de fuentes primarias locales y oficiales, a los que ha seguido un análisis estadístico y cartográfico. Se completa con información actual y contextualizada respecto de las elecciones de 2020. Como conclusiones se desprende que el país se encuentra fracturado entre el norte y el centro, y un sur con amplia presencia de minorías étnicas bien circunscritas. Por ello, es necesario invertir en las regiones en declive prolongado y asegurar la convivencia pacífica en un Estado multicultural como método 
para la prevención de conflicto, frente a un escenario de potencial fragmentación territorial. El análisis interdisciplinar es extrapolable a otros países de la zona gris y constituye una herramienta de ayuda para afianzar la credibilidad europea.

Palabras clave: Moldavia; estatalidad; prevención de conflictos; fragmentación de Estados; zona gris.

\begin{abstract}
The ex-Soviet space represents a contested area where destabilization strategies typical of the gray zone are developed. The analysis of the distribution of ethnic groups, language, economic indicators and electoral geography can serve as a tool to identify those regions that are clearly differentiated from the rest and that may undermine statehood. Moldova is a good example due to the persistence of a frozen conflict (Transnistria), an autonomous region (Gagauzia) and a political polarization between pro-Europeanism and the alliance with Russia. The data comes from local and official primary sources, which has been followed by a statistical and cartographic analysis. It is completed with current and contextualized information regarding the 2020 elections. As conclusions, the country is divided between the north and the center, and a south with a large presence of well-circumscribed ethnic minorities. Therefore, it is necessary to invest in regions in prolonged decline and ensure peaceful coexistence in a multicultural state as a method for conflict prevention, versus a scenario of potential territorial fragmentation. The interdisciplinary analysis can be extrapolated to other countries in the gray area and constitutes a tool to help strengthen European credibility.
\end{abstract}

Key words: Moldova; statehood; conflict prevention; State fragmentation; gray zone.

\title{
1 Introducción
}

Gray (1977) escribía que la Geografía era "el factor fundamental en la política exterior de los Estados ya que es el más permanente". Starr (2013, p. 433) matiza esta afirmación añadiendo que la Geografía "no solo es importante por su relativa estabilidad, sino por su rol en conformar las dinámicas de oportunidades y riesgos", por lo que el enfoque geográfico y espacial adquiere un carácter dinámico y complejo, al tratar sobre espacios, distancias, territorio y fronteras, que pueden cambiar la percepción de la gente o de las élites políticas (Starr, 2013). Esto es más pertinente en el contexto de la globalización, que extiende los movimientos sociales y adapta las motivaciones y reclamos según las características de la comunidad en espacios 
geográficos diferenciados (Nogué \& Vicente, 2001; Svarin, 2016). Las fronteras tienen un significado dual, tanto social como político, sitios de representación del poder estatal, y de confrontación cotidiana de actitudes políticas opuestas (Bürkner, 2020, p. 546). Los procesos de desfronterización y refronterización revisten gran importancia en el este de Europa, donde la ampliación europea provoca controversia y ha modificado la percepción de las fronteras, desde las nacionales semipermeables a constituir la rígida frontera exterior de la UE (Giband \& Vicente, 2018; Bürkner, 2020). De igual manera, las divisiones internas pueden llevar a un dilema de estatalidad: puede producirse una estatalidad disputada (contested statehood), donde una autoridad estatal reconocida no es capaz de mantener un control efectivo de su territorio debido a un conflicto en curso (Papadimitriou \& Petrov, 2012, p. 749). Estas situaciones pueden crear una crisis de seguridad en el seno de Europa, máxime en un contexto de desestabilización de la zona gris, y que potencialmente pueden transformarse en una guerra híbrida. Resulta coherente que, para intentar evitar esta situación, los estudios para la prevención de conflictos sean relevantes. Este enfoque es intrínsecamente transversal, y está relacionado con la seguridad, el desarrollo y la consolidación de la paz y del Estado (Ganson \& Wennmann, 2012). Cuenta con amplia tradición en los estudios geográficos, que conjugan la globalización e identidad en sus diversas escalas (Cairo, 1993; Nogué \& Vicente, 2001; Cairo, 2002; Plaza, 2011; Cairo \& Lois, 2014; Marcu, 2021).

Las operaciones de prevención de conflictos resultan más efectivas si se configuran desde una perspectiva multisectorial y con una implicación amplia de la sociedad. Por ello, el análisis geográfico puede ayudar a identificar escenarios de desigualdad que, manifestados territorialmente, constituyan sectores opuestamente diferenciados dentro de un país (BernabéCrespo, 2020). El principal objetivo de este análisis es identificar zonas sensibles a estrategias de desestabilización e indicar a la clase política la necesidad de atender las desigualdades y mejorar las relaciones entre miembros de la comunidad nacional. Numerosos estudios coinciden en que una de las herramientas que ayudan a la prevención de conflictos territoriales causados por complejas relaciones entre la mayoría y las restantes minorías son los modelos de poder compartido (power-sharing) y autogobierno local (Bieber \& Keil, 2009; Wolff \& Yakinthou, 2012). Un ejemplo pertinente - por características comunes y proximidad geográfica- es el caso de Crimea, donde Dawson (1997) y Sasse (2002), entre otros, estudiaron las relaciones interétnicas y geopolíticas durante la década de los noventa cuando se evitó la aparición de conflicto. 
El concepto de "zona gris" se identifica con aquella área intencionadamente definida por la ambigüedad, y su término hace referencia al espacio situado entre el blanco (paz) y el negro (guerra) (Schadlow, 2014; Kapusta, 2015; Hoffman, 2016; Wirtz, 2017; Jordán, 2018; Englund, 2020). El paradigma actual sobre la ampliación hacia el este de la UE y la OTAN frente a la visión rusa de su "exterior cercano" conforma el establecimiento de una zona gris en suelo europeo, con unas líneas difusas entre la paz y la guerra, donde surgen estrategias desestabilizadoras en un ambiente de ausencia de violencia, aunque con un conflicto latente. La combinación de estas estrategias, entre las que la desinformación adquiere un papel preponderante (Colom, 2020) tiene uno de los mayores éxitos en la generación de descontento social y la movilización de masas. Un ejemplo fue la crisis del Euromaidán de Ucrania (20132014), en el que la competencia entre la OTAN, UE y Rusia por el espacio exsoviético puso de manifiesto la fragmentación sociopolítica del país, resultando en la anexión rusa de Crimea y el conflicto en curso en el Donbás (Pikulicka-Wilczewska \& Sakwa, 2015; Bernabé-Crespo, 2020); y que marcó un antes y un después respecto de la ampliación europea hacia el este (Cadier, 2018; David \& Romanova, 2015; Haukkala, 2015). En la vecina Belarús, las recientes protestas del verano de 2020, catalogadas como una casi "Revolución Blanca", aunque con un origen distinto al Euromaidán y vistas como protestas transversales por la democracia, pueden llevar a la intensificación de la zona gris; por lo que el análisis territorial de las diferencias internas representa una piedra angular en cuanto a la transformación en una guerra híbrida (BernabéCrespo, 2021b).

La competencia por el espacio exsoviético es resultado de una confrontación entre Rusia y la esfera occidental liderada por EEUU y la UE, que ha sido catalogada por algunos autores como una nueva guerra fría (Foxall, 2009; Ojala \& Pantti, 2017), en la que Rusia apuesta por un enfoque multipolar y se posiciona a sí misma como una superpotencia, para lo que es necesario controlar su vecindario próximo (Lanoszka, 2016; Raik, 2019). Desde la perspectiva europea, la fatiga de ampliación motivó el surgimiento de la política europea de vecindad (European Neighbourhood Policy, ENP). Este instrumento se proponía asegurar una estabilidad y seguridad ontológica, difuminando algunas de las fronteras externas europeas según área de actividad, y siempre en reciprocidad tras la adopción de reformas. El ordenamiento geopolítico fue ya concebido en 2003, cuando la Comisión Europea fomentaba el "desarrollar una zona de prosperidad y vecindario aliado" o un "anillo de amigos", con los que establecer relaciones pacíficas y cooperativas (Browning, 2018, p. 103), lo que fue percibido como la creación de 
una zona tampón respecto de espacios ulteriores con más riesgo (Del Sarto \& Schumacher, 2005; Walters, 2004).

Según analistas rusos como Trenin (2016), la visión rusa parece no identificar a las repúblicas exsoviéticas como territorios íntegramente extranjeros ya que el fin de su imperio no fue considerado como tal. La diáspora rusa ofrece el argumento esencial para convertir la cuestión de su seguridad como un elemento primordial para fortalecer a Rusia como el principal actor regional garante de la estabilidad (Kolsto, 1995). El concepto de Русский мир (Russkiy mir), la retórica de la defensa de las minorías étnicas allende de sus fronteras, es el esgrimido para intervenir en su vecindario, apelando al derecho de autodeterminación (Forsberg \& Mäkinen, 2019). ${ }^{1}$ Por tanto, las minorías pueden ser un objetivo de las políticas desestabilizadoras en la zona gris, las cuales aplicadas de forma simultánea pueden generar oportunidades susceptibles de ser aprovechadas por Rusia (Jordán, 2019). Como señala Tsygankov (2015, p. 298), Putin está mostrando al mundo que Rusia es capaz de defender sus intereses, aunque eso ocasione perjuicios como socavar la estatalidad de sus vecinos, como ocurrió en el caso ucraniano.

Radaelli (2004) señala que la europeización, entendida como la integración en cuanto a reglamentos jurídicos, instituciones, estructuras políticas, económicas y niveles de riqueza, siempre ha contado con la oposición de movimientos políticos que se arraigan en el nacionalismo y regionalismo. Por esta razón, el euroescepticismo es un fenómeno inherente a la construcción de la UE desde sus inicios (Bükner, 2020). Recientemente, el caso del "Brexit" puso en relieve la crisis de confianza en la UE, incluso en aquellos países con un nivel de riqueza más elevado. En este sentido, la teoría de los "lugares que no importan" (places that don't matter) ha sido desarrollada por Rodríguez-Pose (2018) y argumenta que el declive prolongado de las regiones ocasiona un auge del populismo, que en la UE se ha traducido en muchos casos hacia la corriente del euroescepticismo. El surgimiento del voto antisistema en general, y euroescéptico en particular, ha atraído la atención de numerosos autores quienes señalan factores individuales como la edad, la educación y la riqueza, o la desigualdad y la ruralidad (Goodwin \& Heath, 2016; Hobolt, 2016; Gordon, 2018; Rodrik, 2018; Martin et al., 2018). Dijkstra et al. (2020) subrayaron que la reciente ola populista y la desconfianza en la UE están teniendo un efecto en la geografía electoral europea. De esta manera, entre 2013 y 2018, el 13,4 \% de los votantes emitieron su voto en las elecciones nacionales legislativas a partidos

1 El cual ha propiciado el reconocimiento de los Estados de facto de Abjasia y Osetia del Sur, o la incorporación de Crimea a la Federación Rusa; si bien no aplicó este criterio en el caso de Kosovo, o internamente con respecto a la crisis chechena. 
que se oponen a la integración europea; porcentaje que asciende al 26,7 \% si se cuentan los partidos que desean un reseteo de la agenda europea.

Para paliar esta situación se argumenta que una mayor inversión en desarrollo debería realizarse para generar estrategias de desarrollo viables y sólidas en aquellas regiones que se han quedado rezagadas (lammarino et al., 2019; Rodríguez-Pose \& Dijkstra, 2020). Como muestra Schraff (2019), la inversión europea en desarrollo regional ha contribuido a reducir el porcentaje de votos a los partidos euroescépticos. Sin embargo, no es suficiente únicamente con invertir, sino que el "cómo" y en "qué" determina su efectividad: la conexión entre la inversión europea en desarrollo regional y la reducción del voto euroescéptico depende en gran manera del tipo de inversión y en su eficacia. Fidrmuc et al. (2019) mostraron que la inversión en áreas rezagadas del Reino Unido fue más bien vista como un subsidio a cambio de "comprar amor" que como una inversión creíble. De igual manera, las expectativas irrealistas sobre la llegada de fondos europeos pueden haber facilitado el crecimiento de posturas descontentas con la UE (Bachtler \& Begg, 2016); al igual que también influye la manera de comunicar e informar sobre la procedencia de estos gastos por parte de los gobiernos nacionales y regionales. En general, Rodríguez-Pose y Dijkstra (2020) recogen que la inversión es más exitosa si se realiza en recursos humanos, investigación, desarrollo tecnológico e infraestructura social. Además de estos hechos, el emergente escepticismo también está asociado a la geoestrategia, el conflicto internacional, las crisis económicas y los problemas migratorios (Bürkner, 2020, p. 551).

Esta es una contribución interdisciplinar (seguridad internacional, derecho internacional público, estudios estratégicos) que otorga a la geografía un papel fundamental en cuanto a la prevención de conflictos, ya que el análisis de las variables consideradas permite caracterizar las diferencias territoriales en un país sometido a una creciente presión geopolítica, la cual también se discute en el presente artículo. Se trata de una aportación original y relevante para la geografía española, sobre un espacio de destacado interés -el este de Europa- para el conjunto europeo y que tradicionalmente ha recibido escasa atención desde la academia española. La hipótesis de este trabajo es que el análisis geográfico puede servir como herramienta para prevenir conflictos, al identificar diferencias internas que puedan ser susceptibles de ser desestabilizadas en el contexto de la zona gris. Su importancia radica en que se trata de prevenir crisis de seguridad, las cuales pueden afectar directamente a ciertos miembros de la UE, e indirectamente al conjunto de la organización. Tras analizar el área de estudio, se procede al análisis de la distribución territorial de etnias y minorías étnicas; de lenguas; de indicadores económicos como la producción agrícola o industrial; de bienestar como el salario o el nivel de desempleo; y un 
recorrido por la geografía electoral moldava reciente, para finalmente elaborar unas conclusiones. El objetivo es identificar lugares de descontento, netamente diferenciados del conjunto nacional, que puedan constituir el germen de un conflicto en caso de una intensificación de las estrategias desestabilizadoras que caracterizan a la zona gris.

\section{Metodología}

Moldavia representa un excelente ejemplo para probar este estudio de caso, ya que por razones geográficas e históricas se ha encontrado en el umbral entre la esfera más puramente europea y la rusa. Presenta, además, un conflicto actualmente congelado (resultado de una guerra civil en tiempos de la desintegración de la URSS), y su contexto político se debate entre una mayor integración hacia la UE o un mayor acercamiento a Rusia. Otros países del espacio exsoviético europeo ya han experimentado procesos de revolución como Ucrania, Georgia, Armenia o Belarús.

Las variables del análisis empleado representan los elementos identitarios de las minorías (etnia y lengua) y los elementos que caracterizan a las regiones en declive (economía y política). Este análisis multinivel mostró un país fragmentado socialmente (Ucrania), cuyos resultados casi opuestos mostraron las grandes diferencias entre el este y oeste, lo que ayudó a la desestabilización y pérdida de estatalidad (Bernabé-Crespo, 2020). Los datos han sido proporcionados por organismos oficiales locales: la Oficina Nacional de Estadística de la República de Moldavia (Biroul Național de Statistică, BNS) y la Comisión Electoral Central de la República de Moldavia (Comisia Electorala Centrala a Republicii Moldova). La división territorial estadística corresponde al raion, que se asemeja al municipio. Se señala la imposibilidad de recabar datos para Transnistria, ya que esta región no está controlada por la República de Moldavia. Entre las variables analizadas, se han escogido entre las demográficas la distribución de la población en 2014 (ya que es el último censo) y su variación desde 1989 (último censo antes de la desintegración de la URSS y la independencia moldava); y la estructura de la población por etnia y lengua materna. Para la caracterización de los sectores primario y secundario, el número de hectáreas cultivadas y la producción industrial manufacturada son los más representativos que ofrece el BNS. En cuanto al desempleo, el indicador que más se ajusta de los que ofrece es la tasa de población inactiva mayor de quince años. El salario bruto mensual es calculado en conjunto para hombres y mujeres, expresado en lei moldavo. El análisis electoral realiza un breve repaso desde la independencia del país, pero se centra en la segunda 
vuelta de las últimas dos elecciones presidenciales, las cuales muestran una mayor polarización al basarse en la elección entre un candidato prorruso y proeuropeo.

\section{3 Área de estudio: contexto histórico y geopolítico}

Moldavia se encuentra en la región del Mar Negro (Figura 1), un área de eminente importancia geoestratégica (Marcu, 2004). El río Dniéster ha sido históricamente una frontera natural, puerta al mundo eslavo respecto del resto de Europa, y que separaba dos grandes esferas socioculturales: la turca musulmana y la rusa ortodoxa. Moldavia (término rusificado de la denominación tradicional rumana Moldova) como entidad estatal no deja de ser un producto reciente y artificial, únicamente independiente desde 1991, y que hunde sus raíces en la confrontación ruso-turca y en la identidad rumana.

Figura 1. Área de estudio y raiones de Moldavia

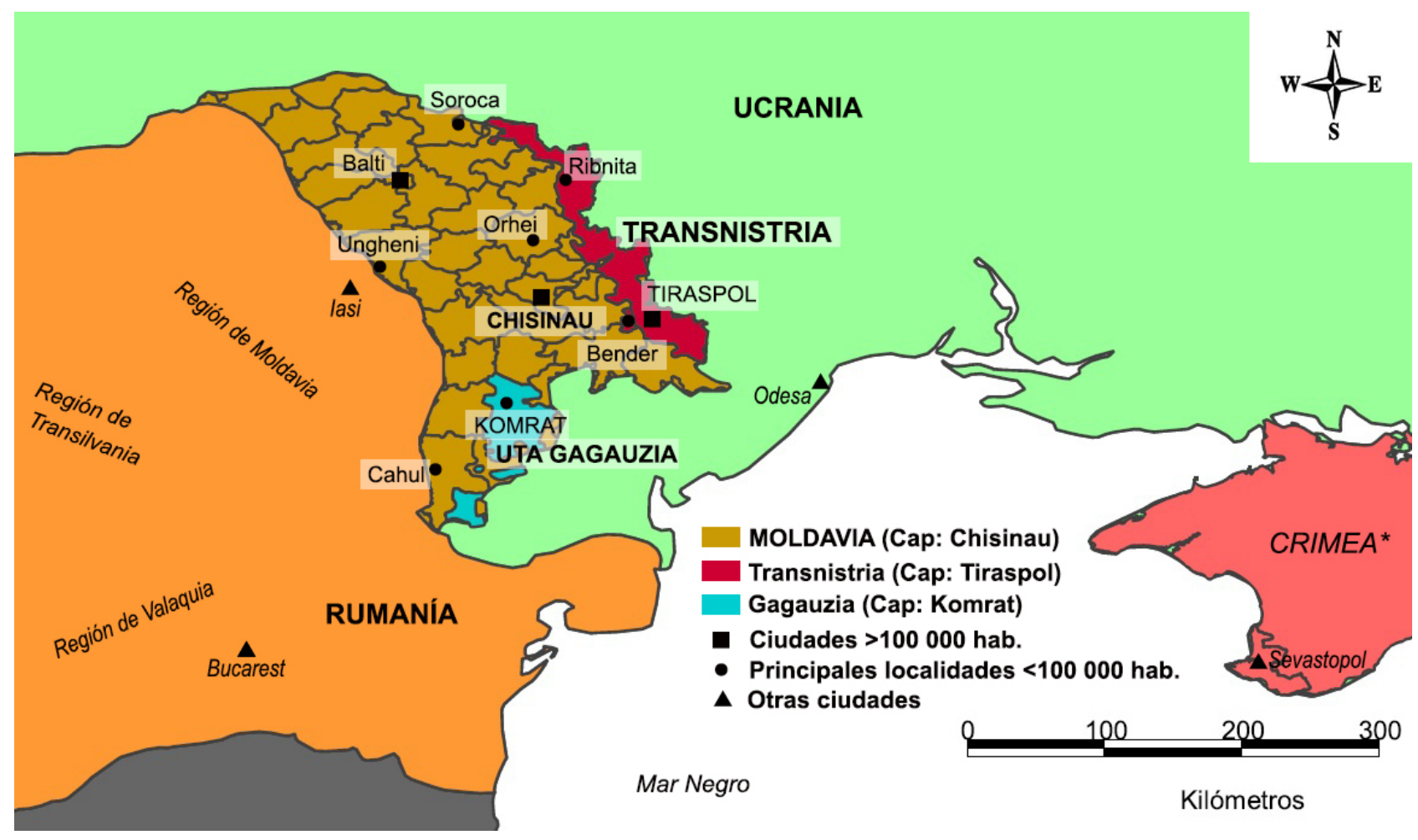

Fuente: elaboración propia

En el siglo XIX, este territorio era disputado entre el dominio otomano y ruso. El histórico Principado de Moldavia era un vasallo de los turcos, que desde siglos atrás hacía frente a las incursiones tártaras. En 1812, el Tratado de Bucarest adjudicó al zar Alejandro I de Rusia la parte oriental del Principado de Moldavia, que llamó Besarabia, comprendida entre los ríos Prut y Dniéster. A este lugar llegaron numerosos búlgaros que habían luchado junto con Rusia, al igual 
que tuvo lugar la inmigración de gagauzos, un pueblo túrquico de confesión ortodoxa; también numerosos disidentes ucranianos y rusos. A pesar de los esfuerzos para la rusificación del territorio, en 1817 el 86 \% de la población era rumanoparlante, o "moldavos" como se llamaban a sí mismos (Hamm, 1998).

El Principado de Moldavia, cuya mayor parte del territorio se encuentra en la actual Rumanía, y cuya capital histórica es lasi, es considerado el germen del Estado rumano. El príncipe moldavo Alexandru loan Cuza unificó en 1859 los principados de Moldavia y Valaquia; en 1881 se constituyeron en un reino al frente del cual estuvo Carol I; y al que tras la I Guerra Mundial se le incorporaría Transilvania. La llamada "Gran Rumanía" se consolidó con la anexión de Besarabia, que declaró su independencia en 1918 tras la Revolución Soviética. Paralelamente, la URSS creó la RSSA de Moldavia, territorialmente en espacio ucraniano, como un esfuerzo para comenzar a liberar Besarabia del capitalismo (King, 1998). La unión de Besarabia al resto de la Gran Rumanía se mantuvo hasta 1940, cuando la URSS la invadió en base al pacto de RibbentropMolotov de 1939. Rumanía aprovechó el contexto de la II Guerra Mundial y las hostilidades entre la Alemania nazi y la URSS para volver a ocupar Besarabia, hecho que en la ribera oriental del Dniéster hizo que la imagen rumana se identificara con el fascismo enemigo (González, 2017). Finalmente, la victoria aliada conllevó el dominio soviético en Besarabia y la URSS decidió unir esta región a Transnistria (la franja oriental inmediata al río Dniéster) para conformar la RSS de Moldavia, que podía prevenir una eventual unificación de Besarabia y Rumanía. Entre 1944 y 1951 se realizaron deportaciones de moldavos desde la RSS de Moldavia hacia Siberia y Kazajstán, intercambiándolos por rusos y ucranianos, con el fin de modificar la composición étnica del territorio (Marcu, 2011).

En los albores de la desintegración soviética, desde Chisinau emanaba un sentimiento de reunificación con Rumanía, sostenido por el Primer Ministro Mircea Druc. Por su parte, Mircea Snegur ${ }^{2}$ apostaba por un nacionalismo moldavo, aunque sin negar las vinculaciones históricas y culturales con Rumanía ni el carácter multiétnico del país (González, 2017). El entonces Frente Popular de Moldavia (FPM) era un partido nacionalista moldavo que, además, demandaba una revisión entre la relación de la lengua moldava y rumana (King, 1994-1995). En 1989, el Soviet Supremo aprobó gracias a la acción del FPM unas leyes lingüísticas que desplazaron al ruso

2 Presidente del Soviet Supremo de la RSS de Moldavia (dentro de la URSS) que, posteriormente, abogó por la independencia de Moldavia y se convirtió en su primer presidente. 
como idioma dominante e introdujeron el alfabeto latino, que prácticamente era la única salvedad que diferenciaba al rumano del moldavo.

En Transnistria y Gagauzia se temía una romanización del país y la reunificación con Rumanía. Empezó a fraguarse, en la ribera oriental del Dniéster, un movimiento secesionista, que tuvo su origen en 1989 con la creación del Consejo Unificado para los Trabajos Colectivos (OSTK), por trabajadores industriales, al frente del cual estuvo lgor Smirnov. Estos organizaron una huelga para conseguir la cooficialidad del moldavo y el ruso, a lo que siguió la retirada de los diputados transnistrios y gagauzos del Soviet Supremo. En 1990 se proclamó la República Moldavia Socialista Soviética de Transnistria, controlada por el OSTK de Smirnov. El gobierno de Chisinau comenzó una ofensiva bélica que tuvo que detenerse en Dubasari debido a la acción de la población civil. El 17 de marzo de 1991, Transnistria y Gagauzia organizaron un referéndum en el que la mayoría votó seguir perteneciendo a la URSS. Sin embargo, la RSS de Moldavia se declaró independiente el 27 de agosto de ese mismo año.

El reconocimiento internacional de Moldavia en 1992 como Estado independiente, en las mismas fronteras que su predecesora RSS, motivó la continuación de la guerra contra Transnistria (guerra civil, ya que de iure es territorio moldavo). En este conflicto, ambas partes han insistido en que se trata de un conflicto político, pero no hay que obviar el componente étnico: como señalan Kaufman y Bowers (1998), los rusos étnicos eran la fuerza dominante en el movimiento secesionista de Tiraspol, mientras que los étnicos moldavos intentaban controlarlo; y las acciones extremistas en ambos bandos generaban el respectivo temor de extinción de la comunidad. A ello se le añade la visión dicotómica entre los defensores del comunismo y los partidarios de un nacionalismo democrático (Kolsto \& Malgin, 1998), por lo que se podría considerar como un conflicto étnico internacionalizado. El hecho de que los rebeldes de Tiraspol contaran con el apoyo, armamento y munición del XIV Ejército Soviético, que estaba afincado en su territorio, consolidó su victoria. Desde entonces, Transnistria opera como un Estado de facto, no reconocido por la comunidad internacional, por lo que otros autores utilizan el término "Estado no reconocido" (Caspersen \& Stansfield, 2011) ${ }^{3}$

Con respecto a Gagauzia, en 1994 el Parlamento moldavo aprobó la Ley de la autonomía gagauza, por la que se creó la Unidad Territorial Autónoma (UTA), además de la legislación

3 Pese a que algunos de este tipo de Estados se reconocen mutuamente, como sucede entre Abjasia, Osetia del Sur, Nagorno Karabaj y Transnistria. Por ello, Kolossov y O'Loughlin (1998) proponen el término "pseudoEstados" y Kolsto (2006) el de "Cuasi-Estados no reconocidos". Para los dos primeros (Abjasia y Osetia del Sur) cabría hablar de "reconocimiento limitado" ya que algunos Estados miembros de la ONU sí los reconocen. 
sobre sus instituciones (Chinn \& Roper, 1998). De esta manera, Moldavia evitó un nuevo conflicto en esta área, que sí está bajo control moldavo, aunque con un estatus que le otorga cierta autonomía.

En 2003, el presidente moldavo Voronin se negó a firmar el Plan Kozak, que se proponía solucionar el problema transnistrio, aunque también posibilitaba la independencia de esta franja o su adhesión a otro Estado si se cumplían ciertas condiciones (Marcu, 2011). La vinculación de Transnistria con Rusia ha sido más estrecha: en 2006 se celebró un referéndum en el que el 97,2 \% de los transnistrios apoyaban la integración en Rusia, y desde 2013, la legislación rusa se aplica en su territorio (González, 2017). En 2015, en Komrat (capital de Gagauzia) se organizó un referéndum en el que el 98,4 \% votó a favor de estrechar lazos con la Unión Económica Euroasiática (EEU) y el 97,2 \% se oponía a la integración en la UE (Beyer \& Wolff, 2016, p. 346).

Actualmente, Transnistria es conocida como "el agujero negro de Europa", donde se documentan delitos como el tráfico de personas, comercio ilegal de armas, drogas y órganos humanos, donde la Interpol no opera ni tampoco se prestan servicios diplomáticos (Sánchez, 2009). La solución al problema transnistrio es un asunto de posiciones enfrentadas, en el que Rumanía, uno de los principales actores, apoya la integridad territorial de Moldavia (Marcu, 2009) y su integración europea, considerada como una deuda moral (Marcu, 2011). Por otra parte, Cojocaru (2006) tras realizar un estudio mediante entrevistas en la Universidad de Tiraspol, concluyó que es difícil reintegrar a Transnistria dentro de una Moldavia federal. Por último, la política exterior rusa de Russkiy Mir, dentro de la visión del ближнеезарубежье (blizhneyezarubezhye, su exterior próximo), hace que Rusia ejerza una destacada influencia para controlar su vecindario. Este se encuentra en disputa, entre una Rusia que se posiciona a sí misma como una superpotencia y que apuesta por un enfoque multipolar, en el que busca ostentar el dominio en su propio espacio; y una ampliación de la UE y OTAN que continúa realizándose hacia el este, incluyendo a países exsoviéticos y antiguos aliados de Moscú. La posición geoestratégica de Moldavia se basa en: ser una república exsoviética encajada entre un país perteneciente a la OTAN (Rumanía) y otro que tiene la integración en la alianza noratlántica como una de sus prioridades (Ucrania) ${ }^{4}$; la oportunidad para la Federación Rusa de aprovechar el conflicto congelado de Transnistria, estrechamente vinculado con Rusia, para ejercer un

4 Como recientemente se propone y se discute la inclusión de Ucrania en el Plan de Acción de Membresía (MAP, Membership Action Plan). 
control sobre el terreno inmediato ${ }^{5}$; y la posibilidad de servir como posición para un eventual corredor que enlace Transnistria con el Donbás, asegurando el dominio sobre Crimea. ${ }^{6}$ Pero, además, Turquía puede competir por este espacio haciendo valer su influencia sobre la población gagauza, de etnia túrquica.

\section{Resultados}

Para contextualizar la interpretación de las variables es necesario referir al panorama demográfico de Moldavia (Figura 2), un país que según el último censo de 2014 contaba con 2 804801 habitantes $^{7}$, la mayoría de los cuales viven en Chisinau (469 402, el 16,73 \% del total). El territorio controlado por las autoridades moldavas se compone de 35 distritos (incluyendo la UTA de Gagauzia). Destaca la importancia de esta última, que constituye el segundo distrito más poblado del país con 134535 habitantes. Por ciudades, Balti (102 457 hab.) es el segundo centro urbano, aunque en conjunto, los distritos de Cahul y Hancesti le superan. La mayoría de la población se concentra en el centro oriental del país, próxima a la ribera del Dniéster y en el sur del país, tanto a orillas del Prut como en los campos gagauzos. Por el contrario, el norte del país sostiene una población más reducida. También es interesante conocer la evolución de la población desde el colapso de la URSS: al igual que en otros países exsoviéticos, una de las repercusiones fue el descenso de población motivado por un empeoramiento de la calidad y esperanza de vida, así como la emigración hacia otros países europeos. En Moldavia se observa una reducción del -23,32 \% de sus habitantes desde 1989 (cuando contaba con 3657665 habitantes). El norte destaca como área donde el descenso de población es más acusado, de más del 25 \%. Sin embargo, las mayores reducciones se dieron en las dos principales ciudades: Balti $(-36,55 \%)$ y Chisinau $(-39,11 \%)$. La capital pasó de contar con más de 770000 habitantes en 1989 a tener en la actualidad menos de 470000.

5 En este sentido, Rusia también ha aprovechado la reciente guerra de Nagorno Karabaj de 2020 para establecer pacificadores en el Cáucaso sur.

6 Con especial atención al Budjak, el óblast con mayor diversidad étnica de Ucrania y geográficamente menos accesible desde Ucrania: conectado mediante dos carreteras de las cuales una discurre por territorio moldavo.

7 No incluye la población de Transnistria. 
Figura 2. Distribución de la población en Moldavia

(según censo de 2014) y variación desde 1989

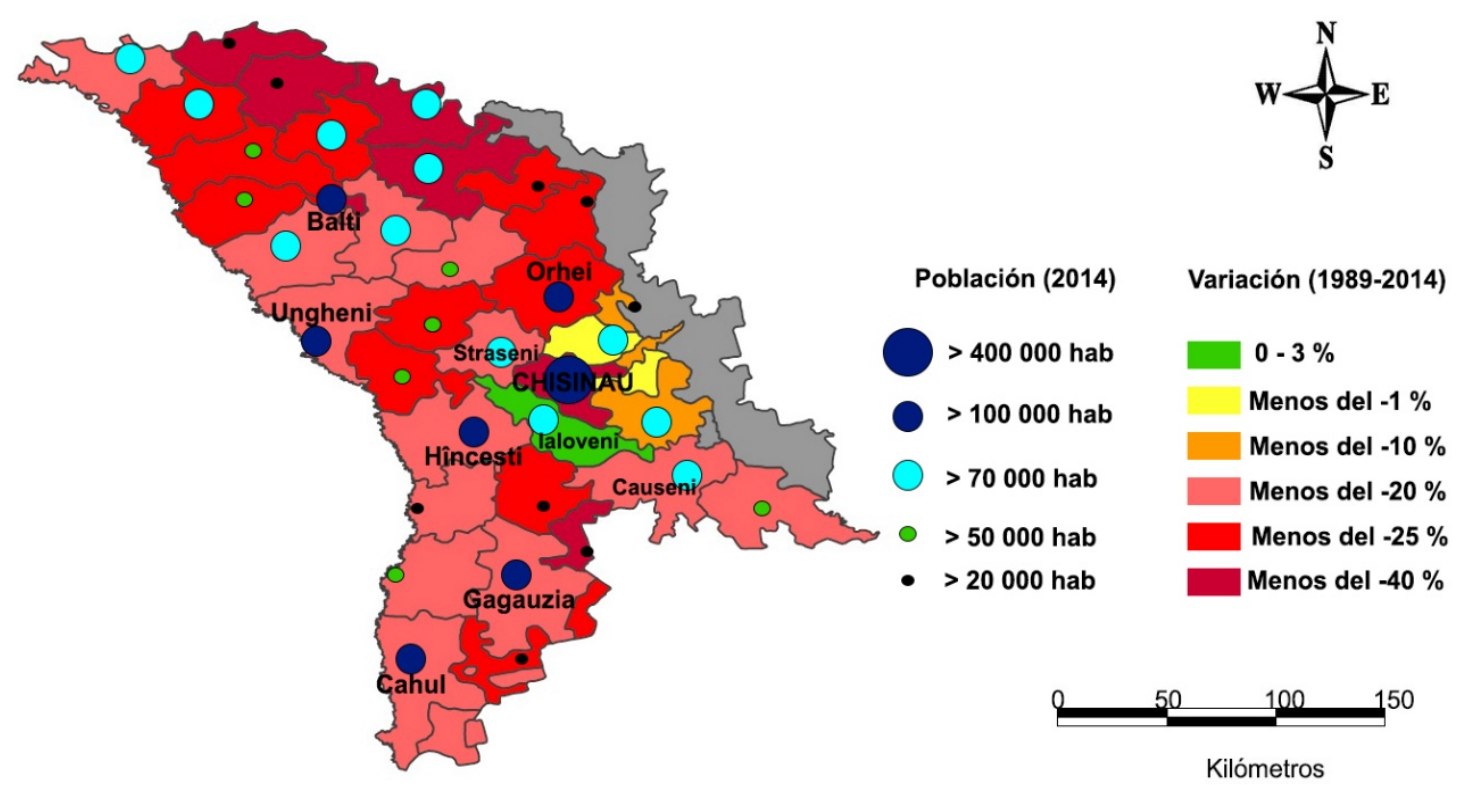

Fuente: elaboración propia a partir de Biroul Național de Statistică (2020)

\subsection{Distribución étnica y lingüística en Moldavia}

El último censo disponible, de 2014, permitía contestar a la etnicidad de forma diferenciada entre "rumano" o "moldavo". En este trabajo se han considerado sinónimos debido a su difícil distinción, que simplemente difiere en el sentimiento más o menos nacionalista. En el conjunto de Moldavia ${ }^{8}$, el $82,1 \%$ de sus ciudadanos tienen un origen moldavo o rumano (Figura 3). Las principales minorías son los ucranianos $(6,6 \%)$, gagauzos $(4,6 \%)$, rusos $(4,1 \%)$, búlgaros $(1,9$ $\%)$ y gitanos $(0,3 \%)$. Los rumanos-moldavos son mayoría en todos los distritos del país, salvo en el sur: en Taraclia (donde los búlgaros son el 66,1\%) y en Gagauzia (83,8 \% de gagauzos). Búlgaros y gagauzos prácticamente se encuentran singularizados en sus respectivos distritos, y fuera de ellos solo están presentes en la multicultural Basarabeasca ${ }^{9}$. Las mayores proporciones de rumanos-moldavos se dan en Nisporeni y Telenesti (ambos 98,4 \%), en el centro del país. Las minorías de ucranianos se encuentran principalmente en el norte del país: en Ocnita son el 25,3 $\%$, y en Briceni el 22,5\%, y superan el 15 \% en Balti, Edinet, Rîscani y Glodeni. La mayor proporción de rusos se localiza en Balti (16\%), la segunda ciudad del país, en la que los

8 Estas referencias al "conjunto del territorio" no incluyen a Transnistria, ya que no existen datos.

9 Basarabeasca: 72 \% rumanos-moldavos; $8,5 \%$ rusos; 7,4 \% gagauzos; $5,5 \%$ ucranianos; 5 \% búlgaros; 1 \% gitanos. 
rumanos-moldavos son apenas el $63 \%$. Se deduce que, étnicamente, se observan las siguientes unidades: Gagauzia, poblada por Gagauzos; Taraclia, por búlgaros; el norte, con amplia minoría de ucranianos y rusos, y una proporción más reducida de moldavos-rumanos; y un centro del país donde prácticamente constituyen la totalidad de la población.

\section{Figura 3. Estructura étnica en Moldavia}

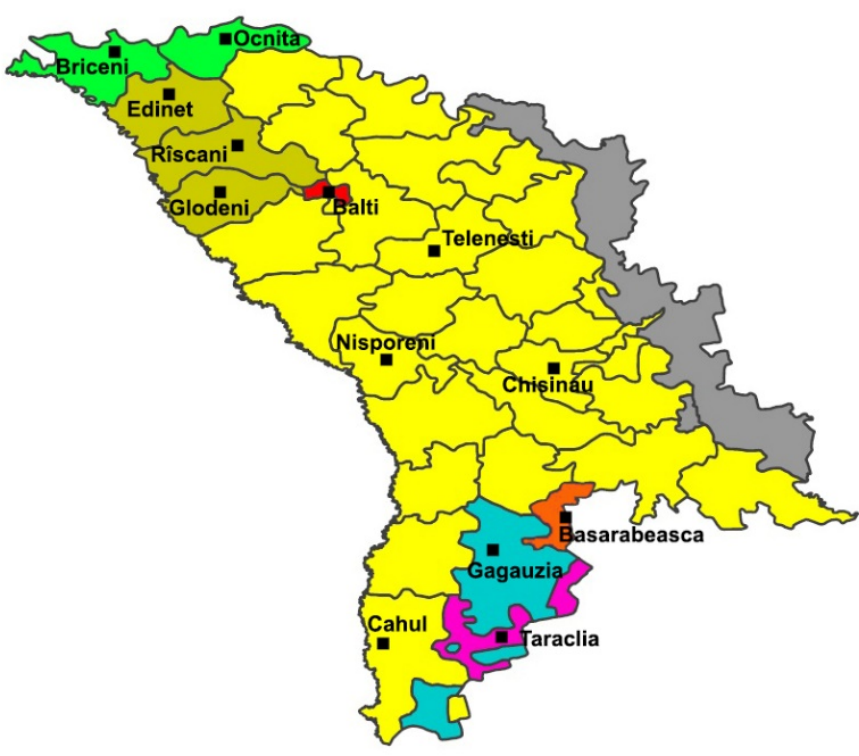

\section{Estructura étnica}

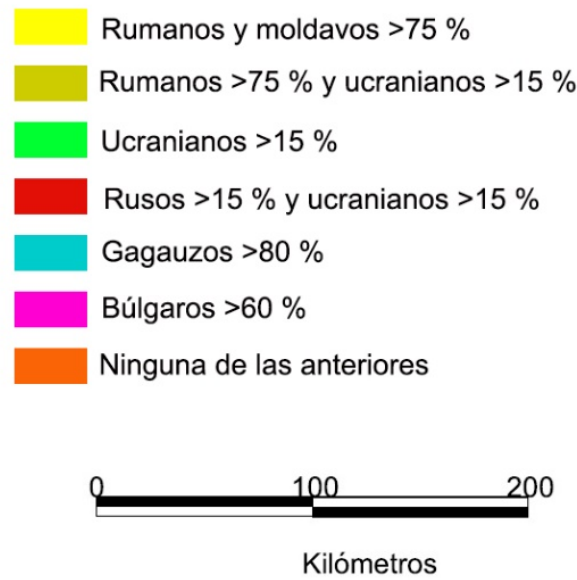

Fuente: elaboración propia a partir de Biroul Național de Statistică (2020)

El moldavo o rumano (semejantes) es el idioma nativo del 80,2 \% de la población nacional, seguido del 9,7 \% del ruso, 4,2 \% gagauzo, 3,9 \% ucraniano, 1,5 \% búlgaro y 0,3% romaní (Figura 4). El rumano es la lengua madre mayoritaria en todos los distritos (máximos en Nisporeni y Telenesti con el 98,5 \%), salvo en Gagauzia (solo el 3,7 \%, frente a un 80,4 \% del gagauzo) y en Taraclia (12,3 \%, frente a un 63,9\% del búlgaro). El gagauzo y búlgaro apenas son hablados fuera de sus respectivos distritos. El siguiente porcentaje de menor frecuencia del rumano como lengua materna es Balti, donde solo representa un 53,6 \%, y donde el 41,5\% elige el ruso. Este último idioma es especialmente importante en Chisinau (20,8 \%), Basarabeasca $(20,5 \%)$ o Taraclia $(14,4 \%)$, lo que sugiere que, además de los étnicamente rusos, otras minorías eligen el ruso como idioma antes que el rumano (por ejemplo, en Gagauzia el ruso representa casi el 10 \%). El ucraniano sí parece estar más restringido a 
aquellos distritos con mayor proporción de ucranianos, como Ocnita, donde lo habla el 21,3 \%, Briceni, el 19 \% o Rîscani, el 14,6\%. Otros distritos son más plurilingües como Edinet ${ }^{10}$.

Figura 4. Estructura de la población por lengua materna en Moldavia

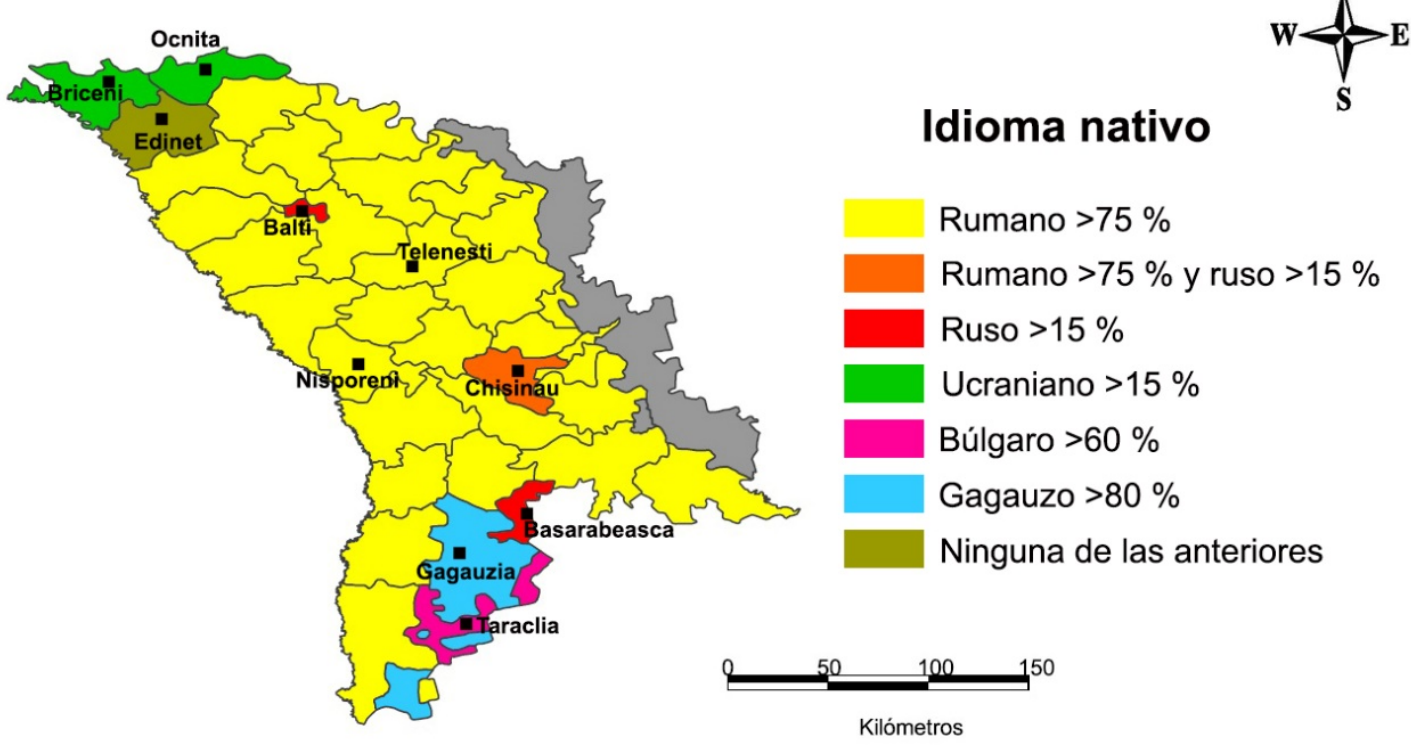

Fuente: elaboración propia a partir de Biroul Național de Statistică (2020)

\subsection{Indicadores económicos}

Realizando una aproximación a la importancia del sector agrario, la Figura 5 muestra la superficie cultivada (ha) en cada distrito respecto del total nacional. Se observa que las mayores proporciones de tierras en cultivo se localizan en el sur y norte del país. Destaca Gagauzia, la única entidad situada en el primer cuartil (el 9,42\% de las tierras cultivadas en Moldavia se encuentran en Gagauzia, el mayor porcentaje), seguida de Cahul (5,86 \%) y Floresti (5,38 \%). El menor porcentaje se da en Balti $(0,11 \%)$, aunque este es un municipio pequeño y urbano. Le sigue Calarasi $(0,12 \%)$ y otros distritos del centro, donde las tierras en cultivo son más reducidas: aquí se encuentran los mayores bosques y las mayores elevaciones montañosas del país.

Moldavia es un país débilmente industrializado y el gran peso del sector industrial recae en la capital Chisinau, que aglutina el 50,7 \% de la producción industrial manufacturada del país (Figura 6). A gran distancia le sigue Balti, con el $13 \%$, segundo polo industrial de Moldavia. El 
resto del país apenas tiene importancia industrial, con valores inferiores al 2,5\% en todo el territorio restante, e incluso inferior al 1 \% en gran parte del país. Las referencias disponibles sobre Transnistria arrojan que, aunque solo representa el 8 \% del territorio moldavo, llegó a significar el 40 \% de la producción industrial y el 90 \% de la eléctrica, fruto de la inversión soviética (Mackinlay \& Cross, 2003, 135), destacando la producción de acero y coñac.

Figura 5. Total de superficie cultivada en Moldavia en 2019 (\%)

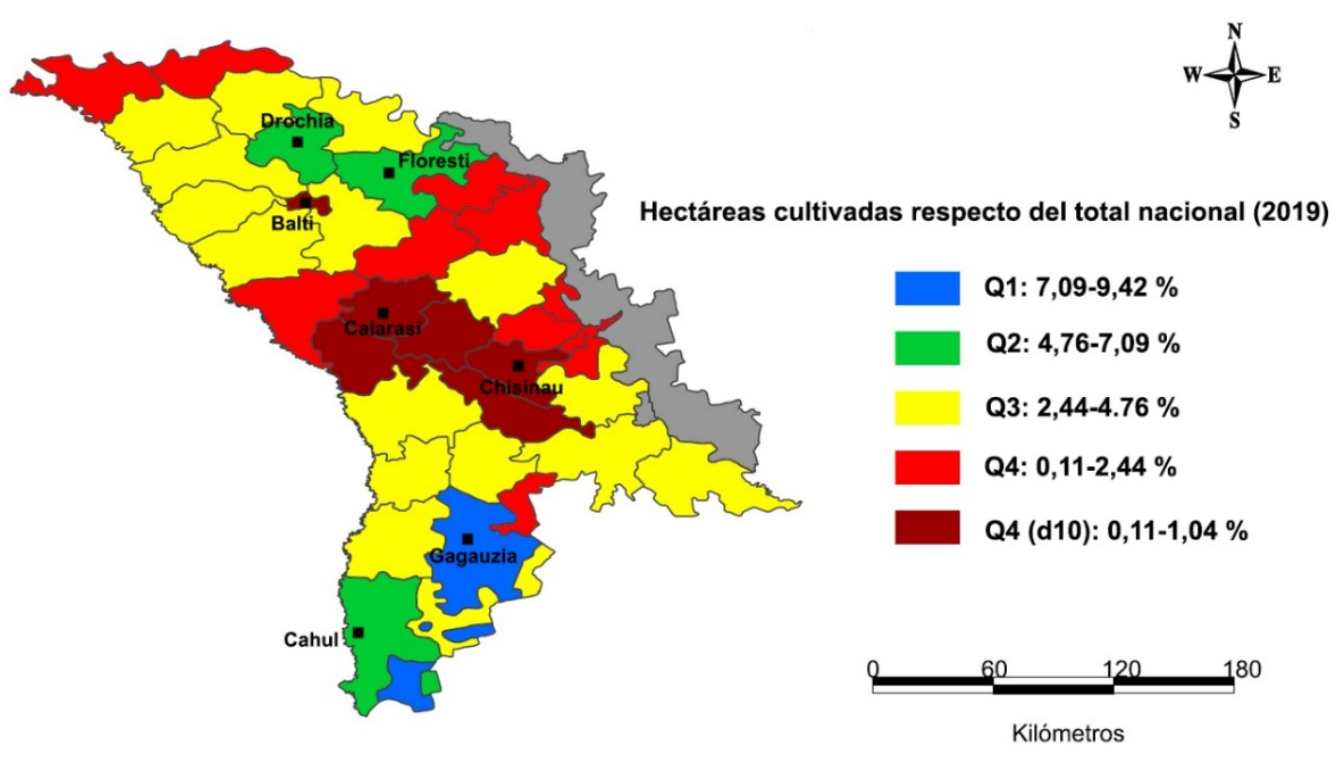

Fuente: elaboración propia a partir de Biroul Național de Statistică (2020)

Figura 6. Producción industrial manufacturada en Moldavia en 2019 (\%)

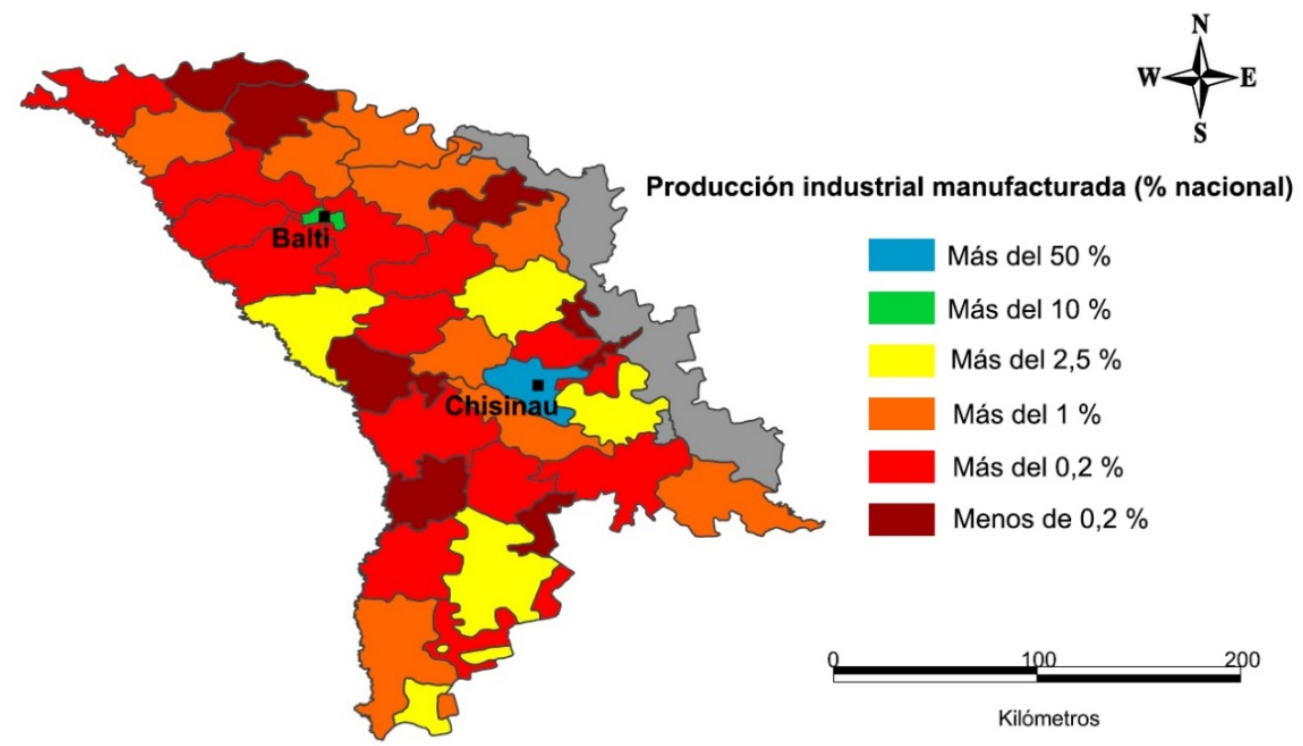

Fuente: elaboración propia a partir de Biroul Național de Statistică (2020) 
La moneda nacional moldava es el lei moldavo ( $1 €$ equivale a 21 lei aproximadamente), y el salario bruto mensual es de unos 7233 lei $(342 €)$ de media. Sin embargo, estos son más altos en Chisinau, donde llegan a los 8686 lei (411 €), seguidos de Balti con 6863 lei (324 €). La mayor parte del territorio se encuentra por debajo de los 5912 lei (280 €), el último cuartil. La situación es peor en aquellos municipios que constituyen el último decil: inferior a 5357 lei (254 $€)$, y el último lugar lo ocupa Basarabeasca con 4987 lei $(236 €)$. En general, se observa la relación entre la actividad industrial y de servicios y el resto de país de economía precaria y agrícola (Figura 7).

Figura 7. Salario bruto mensual en leis moldavos (2019)

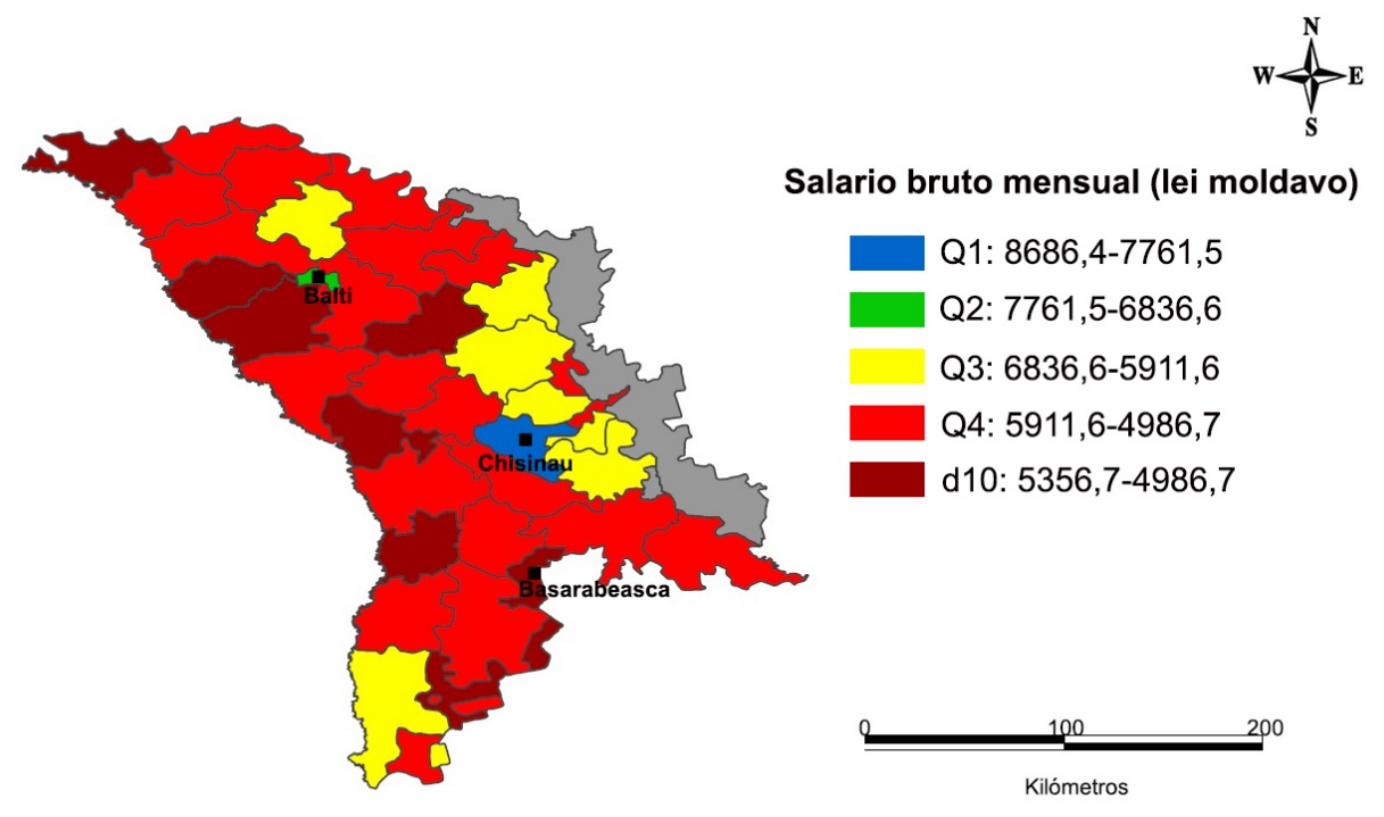

Fuente: elaboración propia a partir de Biroul Național de Statistică (2020)

Otro indicador interesante es conocer el paro en Moldavia, para lo cual la Oficina de Estadística moldava remite a la tasa de población mayor de 15 años inactiva (Figura 8). Se observa que las menores tasas de inactividad se localizan en Chisinau (399 por mil) y Causeni (419 por mil); mientras que las mayores se dan en Rîscani (641 por mil) y Ocnita (635 por mil). En general, en el sur, un área mejor comunicada y que soporta las principales vías comerciales que enlazan Chisinau con Odesa (y siguen hasta Kiev y Bucarest) parece haber más población activa, mientras que el norte parece presentar una tasa de inactividad mayor. 


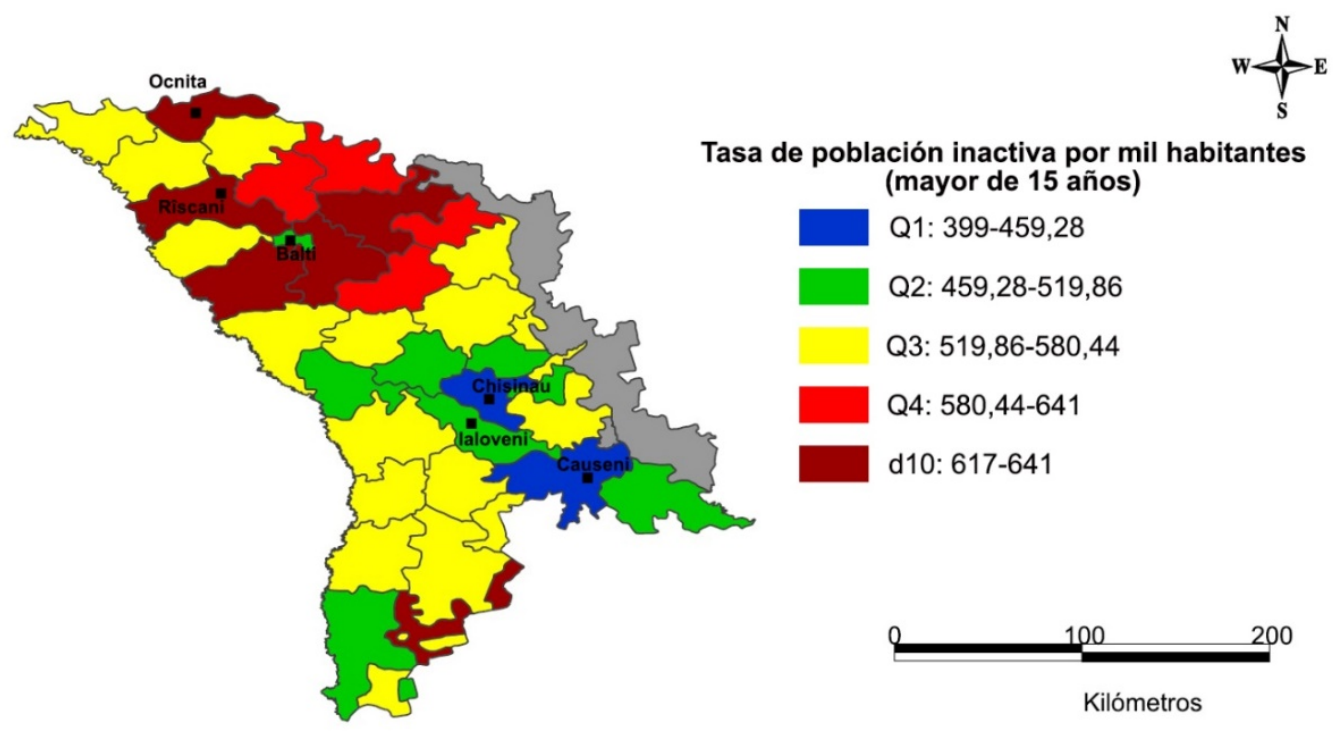

Fuente: elaboración propia a partir de Biroul Național de Statistică (2020)

\subsection{Resultados electorales en Moldavia}

El análisis electoral desvela profundas diferencias desde 1996. Previamente, en 1991 Mircea Snegur consiguió la Presidencia, si bien era el único candidato. En 1996, cuando concurría con otros rivales, Snegur obtuvo sus mejores resultados en distritos del centro y sureste. El candidato del Partido Comunista, Vladimir Voronin, lo hizo en distritos del norte y del sur como Gagauzia, Taraclia, Drochia o Cahul. Sin embargo, la segunda vuelta fue disputada entre Snegur y Petru Lucinschi (candidato independiente, aunque vinculado al Partido Agrario). Voronin había sido eliminado y sus votos se trasvasaron hacia Lucinschi, que terminó ganando (con porcentajes superiores al $90 \%$ en Gagauzia). La mayor frecuencia de voto en las regiones del norte y sur por el Partido Comunista (PCRM) también se repitió en las legislativas de 1998, mientras que en el centro del país triunfaban coaliciones cristianas, aperturistas y nacionalistas. Este patrón se observa sucesivamente en las sucesivas elecciones, como en 2005 o 2010 (Bernabé-Crespo, 2020, p. 276). Desde 2011, el PCRM se ha visto reemplazado por el Partido Socialista (PSRM), aunque con mismos lazos prorrusos, al que influyentes dirigentes como lgor Dodon se traspasaron, y las elecciones de 2014 ya reflejaron tal sorpasso; y la fragmentación de partidos proeuropeos y liberales, siendo el más importante el Partido Liberal Democrático (PLD).

En las elecciones de 2016 (Figura 9), Dodon (candidato del PSRM) de ideología prorrusa se medía contra Maia Sandu (candidata del Partido Acción y Solidaridad, PAS), proeuropea y núcleo del anterior PLD. Dodon resultó vencedor por un ajustado margen (52,11 \% de los votos 
totales). Sus mayores apoyos los consiguió en Gagauzia (98,89\%), Taraclia $(96,11 \%$ ) y Ocnita $(84,75 \%)$, así como una amplia victoria en los distritos del norte del país, entre los que se encuentra la segunda ciudad más importante, Balti (77,65 \% a favor de Dodon). La victoria de Dodon fue posible gracias a que consiguió la mayoría de "swing districts" (en comparación con las mediáticas elecciones estadounidenses y los "swing states"). En Leova y Stefan Voda ganó por la mínima (50,05 \%), en Cahul por 51,24 \% y Causeni (54,79 \%). Maia Sandu ganó Cimislia por 52,98 \%; y su mayor caladero de votos fue el centro del país, destacando laloveni (75,34\%), Straseni $(68,39 \%)$ y Telenesti $(66,07 \%)$. También ganó en la capital Chisinau $(61,36 \%)$.

Figura 9. Resultado de las elecciones presidenciales de 2016 ( $2^{\mathrm{a}}$ vuelta)
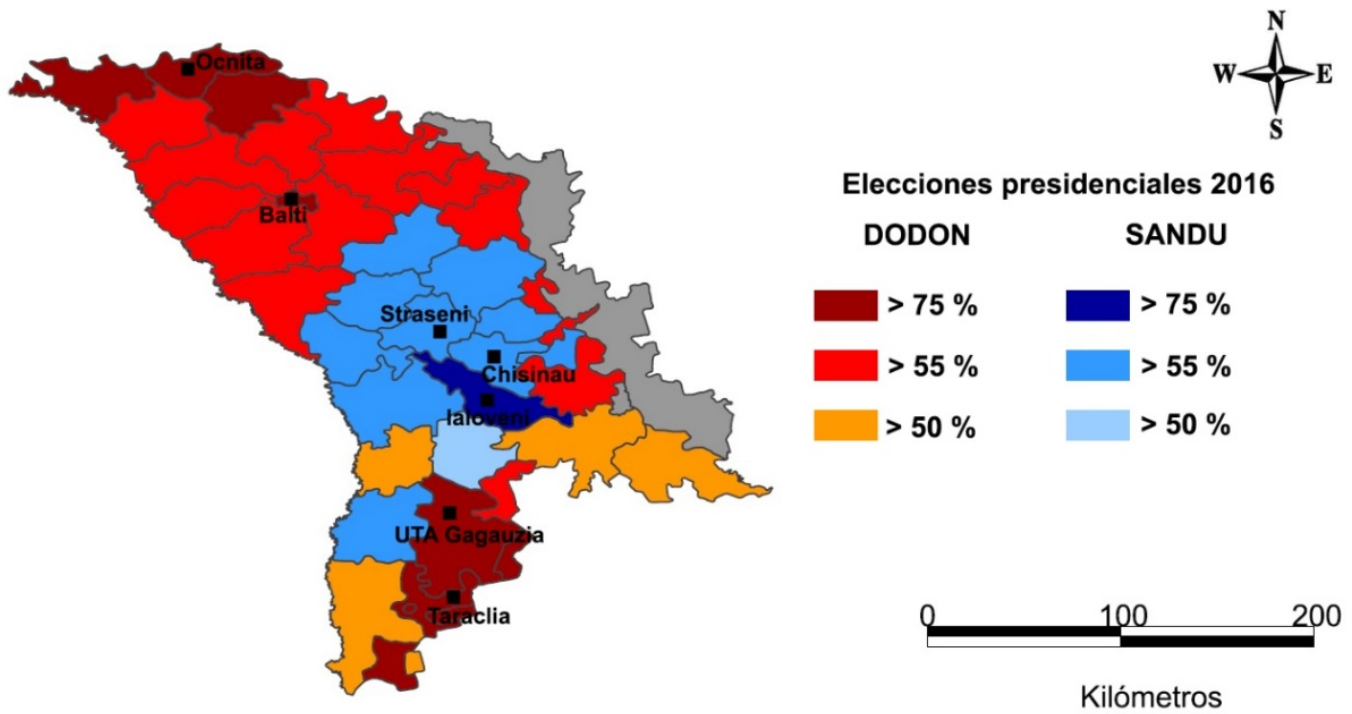

Fuente: elaboración propia a partir de Comisia Electorală Centrală a Republicii Moldova (2020) ${ }^{11}$

En 2020 volvían a medirse Dodon contra Sandu, y esta vez ganó la proeuropea con el 57,72 \% de las papeletas (Figura 10). El voto de la diáspora moldava en el extranjero supuso su mayor baza, ya que el 92,94 \% fueron favorables a Sandu, en un récord de voto extranjero que llegó a significar el $16 \%$ del total. El centro del país continuó siendo su terreno más fértil, aumentando sus mayorías en laloveni $(80,37 \%)$, Straseni $(73,16 \%)$ y Telenesti $(72,18 \%)$. Recuperó todos los distritos que Dodon había ganado por la mínima en las anteriores elecciones (swing districts de Cahul, Causeni, Leova, Stefan Voda) y arrebató otros feudos de Dodon: Ungheni $(55,11 \%)$, Anenii Noi $(54,43 \%)$, Rezina (53,54\%), e incluso Singerei (50,83\%), adyacente a Balti.

11 Disponible en: https://a.cec.md/ro 
Paradójicamente, Sandu empeoró su resultado en la capital (59,70 \%). Por su parte, Dodon continuó siendo el abrumador vencedor en Gagauzia (94,59 \%), Taraclia (92,95 \%), en Transnistria $^{12}(85,80 \%)$ y en Ocnita $(80,74 \%)$. Los distritos del norte fueron los que se mostraron nuevamente más favorables a la victoria del prorruso, aunque en Balti empeoró su resultado y solo llegó al 61,08 \%. Estas últimas dos elecciones prueban que Moldavia sigue estando dividida entre un norte y sur que mayoritariamente vota a partidos de ideología prorrusa, mientras que en el centro predomina el apoyo proeuropeo.

Figura 10. Resultado de las elecciones presidenciales de 2020 ( $2^{\mathrm{a}}$ vuelta)
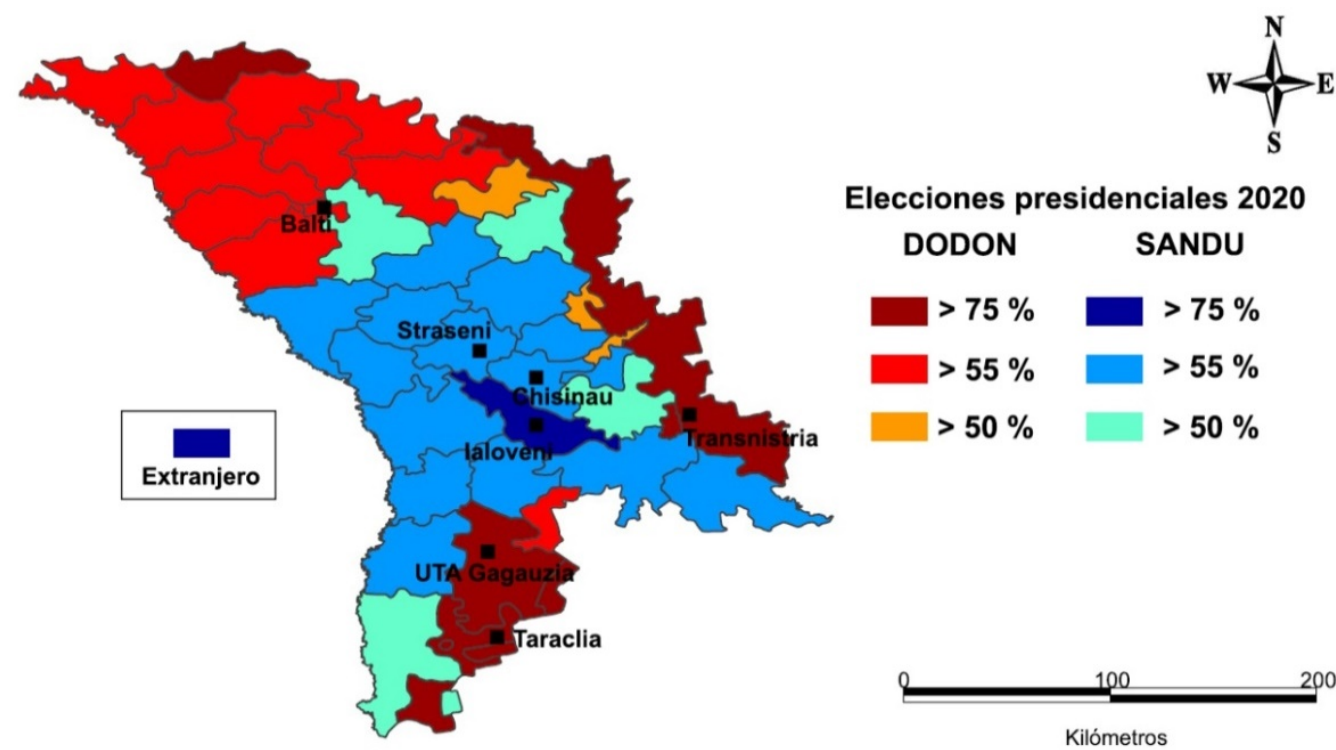

\section{Elecciones presidenciales 2020}

DODON SANDU
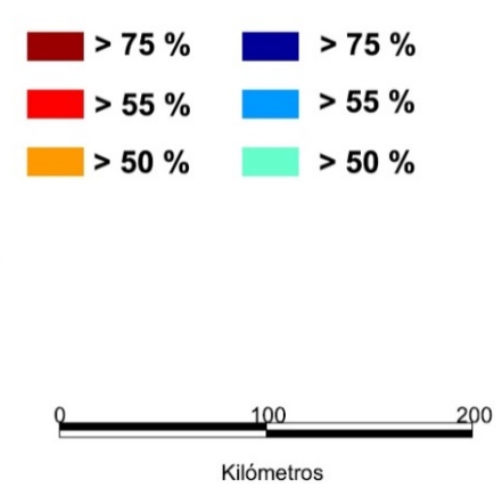

Fuente: elaboración propia a partir de Comisia Electorală Centrală a Republicii Moldova, Rezultatele alegerilor $(2021)^{13}$

\section{Discusión}

Teniendo en cuenta las diferencias internas en los niveles estudiados, se desprende que el centro del país está más poblado, es mayoritariamente étnico rumano, donde predomina la lengua rumana, con menor importancia de la agricultura y el polo industrial de Chisinau (y mayores salarios donde se concentra esta actividad), menor tasa de inactividad y mayor éxito de partidos proeuropeos. En el norte y en el sur, Moldavia está más débilmente poblada (el norte

12 Antes de estas elecciones no se tienen datos oficiales de participación en Transnistria de las elecciones moldavas. Wilson (2020) estima que solo unos 31000 transnistrios votaron en la segunda vuelta, la mayoría de ellos votando en conjunto y cruzando la frontera en autobuses fletados.

13 Disponible en https://rezultate.cec.md/ 
sufre una pérdida de efectivos), pero en estos lugares es donde se concentran mayoritariamente sus minorías étnicas: ucranianos y rusos en el norte, gagauzos y búlgaros en el sur. En estas regiones es preferido el ruso ante el rumano como lengua por las minorías, y la agricultura concentra sus mayores extensiones. Por el contrario, la presencia industrial es casi imperceptible (a excepción de Balti), lo que se traduce en que su economía comporta unos salarios más bajos y mayores tasas de inactividad (ayudada por la emigración de jóvenes a espacios más dinámicos). El norte y el sur representan los feudos tradicionales de los partidos prorrusos, como muestran los resultados electorales analizados. Estas divisiones internas pueden producir crisis de la estatalidad (contested statehood), al acentuar diferencias en la identidad y el bienestar o declive de las regiones en retroceso (los lugares que no importan). Es por ello que resulta de gran interés poder anticiparse a situaciones de conflicto motivadas por competencias geopolíticas, máxime en un contexto de la zona gris y de competencia por el espacio exsoviético, en el cual Moldavia está inserta.

La aproximación a Europa por parte de Moldavia ha dependido del tipo de gobierno elegido. La política de vecindad europea (ENP) y su instrumento, el Eastern Partnership (EaP) han sido vistos por los proeuropeos como una fase previa al reconocimiento de la candidatura de adhesión (Moldavia todavía no es reconocido como candidato oficial ni potencial). Sin embargo, en 2012 fue considerado como "el socio más comprometido en el EaP" y "preparada para una perspectiva europea clara" (Groza, 2019, p. 44). A pesar de ello, los escándalos de corrupción internos hicieron que quedara rezagada en la senda europea. Los prorrusos, por el contrario, recelan del acercamiento a Europa. En declaraciones de Voronin (PCRM), el EaP le recordaba a una nueva "Comunidad de Estados Independientes, una nueva CEI controlada por Bruselas y que formaba un anillo alrededor de Rusia" (Kommersant, 2009). Por parte rusa, la competencia se traduce en ciertas maniobras de zona gris, como las que relatan Cordesman \& Hwang (2020, p. 12), entre las que se destacan la negativa a la retirada de tropas en Transnistria, las prohibiciones de importaciones de carne, frutas, verduras y productos enlatados desde Moldavia - de las cuales Gagauzia y Transnistria fueron exentas (The Guardian, 2014)-, o los cortes en el suministro de gas, además de la desinformación de los medios de comunicación. Económicamente, Moldavia es ahora más dependiente de la UE debido al efecto de la zona de libre comercio (Deep and Comprehensive Free Trade Area, DCFTA) que se firmó en 2016, parte del Acuerdo de Asociación entre Moldavia y la UE. De este modo, el 70 \% de las exportaciones de Moldavia se dirigen a la UE; mientras que las exportaciones a los Estados de la CEI han disminuido un 47 \% desde 2014 (Groza, 2019, p. 46). Entre los más beneficiados se encuentra 
el sector agrícola (vino, miel, semillas de girasol), con un incremento del $44 \%$ de las exportaciones hacia la UE, a donde ha redirigido su mercado tras las sanciones impuestas por Rusia al vino moldavo y otros productos agrícolas.

Los procesos electorales en Moldavia también han reflejado las tensiones geopolíticas y la competencia por este espacio. El Servicio de Inteligencia de la Federación Rusa emitió un comunicado acusando a EEUU de interferir en las elecciones moldavas (Служба внешней разведки Российской Федерации, 2020) e incluso de instigar a una revolución de color para deponer a Dodon, afín al Kremlin (Balkan Insight, 2020a). Las elecciones de 2020 fueron vistas como una elección entre el Este y el Oeste, donde Dodon contaba con el apoyo explícito de Vladimir Putin, y Sandu del Partido Popular Europeo (EPP) (Balkan Insight, 2020b). Sandu centró su discurso en la lucha contra la corrupción, pero también en un mayor acercamiento con la UE (The Washington Post, 2020). En una entrevista a la BBC el día después de ser proclamada vencedora, Sandu se mostró partidaria de una unión con la UE (EI Mundo, 2020) y declaró que "tenemos el derecho de elegir lo que queremos para nuestro país" (BBC, 2020); al igual que llamó a la retirada de fuerzas rusas en la región de Transnistria, que deberían ser reemplazadas por una misión de observadores de la OSCE (The Moscow Times, 2020). Ello fue seguido de las declaraciones del Kremlin, añadiendo que "cambiar el statu quo en Transnistria podría conducir a una grave desestabilización" (Tass, 2020). ${ }^{14}$ Por último, el Primer Ministro lon Chicu, aliado de Dodon, dimitió el día previo a que Sandu tomara el cargo como nueva presidenta (Financial Times, 2020). ${ }^{15}$

Por su parte, el presidente turco Erdogan parece estar asumiendo el "neo-otomanismo", tratando de recuperar la influencia perdida en su esfera y convertir a Turquía en una potencia regional (Albentosa, 2017). En este sentido, sus lazos étnicos y culturales con Gagauzia se han materializado en el despliegue del soft power, como una creciente inversión económica incluyendo la construcción de hospitales, escuelas y centros culturales (Daily Sabah, 2019) o la apertura de un consulado turco en Comrat (Daily Sabah, 2020). En comedida confrontación con Rusia, Turquía podría competir por Gagauzia como un espacio donde socavar la influencia rusa en el Mar Negro.

14 Si bien en junio de 2018, la Asamblea General de las Naciones Unidas ya adoptó una resolución en la que instaba a Rusia a retirar sus tropas en el territorio de la República de Moldavia (UN, 2018).

15 Sandu centró su campaña en la lucha contra la corrupción y declaró que se necesitaban nuevas elecciones parlamentarias (el Partido Socialista de Moldavia tiene mayoría en el Parlamento). 
La integración europea ha sido a menudo percibida en Moldavia como una elección geopolítica entre el Este y el Oeste. Según la última encuesta europea sobre Moldavia (Annual Survey Report, 2020), la mayoría de moldavos (61\%, la mayoría rumanoparlantes y que se encuentran en el centro y sur del país) tienen una imagen positiva de la UE, un 29 \% se siente neutral (más frecuentes entre los rusoparlantes y otras lenguas, localizados en el norte), y solo un 9 \% tiene una mala imagen del club europeo. Ello pone de manifiesto la fractura que existe la composición del país por etnia, lengua y nivel de desarrollo. Si el mapa electoral es contemplado como un plebiscito de la integración europea, el análisis de sus votantes muestra las diferencias geográficas que los separa. Es, en este sentido, donde deben realizarse esfuerzos para uniformizar el país en cuanto a protección de los derechos de las minorías y del desarrollo de las regiones. En este sentido, el informe elaborado por Groza et al. (2018) señala que la falta de políticas convincentes para incluir a representantes de comunidades etno-culturales impide la movilidad social de las minorías étnicas, a la misma vez que apuntaba que las élites moldavas suelen explotar y profundizar la división, presentando frecuentemente a los otros grupos étnicos como una amenaza.

La encuesta arroja un país dividido entre las actitudes proeuropeas y prorrusas, con diferencias significativas en cuanto a la lengua nativa: el 68 \% de los rumanoparlantes apoyan la UE mientras que el $70 \%$ de los rusoparlantes son neutrales (55\%) o directamente se oponen (14 \%). De igual manera, los medios de comunicación en ruso son la fuente de información preferida por los ciudadanos neutrales (73\%) y la mayoría de ellos tienen a confiar más en la UEEA (Unión Económica Euro Asiática, promovida por Rusia), en un $45 \%$.

Debido a que las estrategias de desestabilización de la zona gris incluyen, en última instancia, la movilización de las masas para socavar la estatalidad, es necesario realizar acciones de prevención del descontento que puedan provocar una crisis de seguridad, la cual atañe no solo a la propia Moldavia, sino también a la UE. Las regiones del norte y sur de Moldavia precisan de una inversión destacada para evitar el prolongamiento de unas regiones que parecen olvidadas, donde la economía es esencialmente agraria, con nula presencia de industria y unos indicadores socioeconómicos deficitarios, incluso para estándares de la propia Moldavia. Como se ha señalado, estas inversiones deben ir priorizadas hacia los recursos humanos, investigación, desarrollo tecnológico e infraestructura social, al igual que establecer unas adecuadas estrategias de comunicación: es necesario un mayor conocimiento social sobre los desembolsos europeos y hacer visible las inversiones europeas, especialmente en aquellos lugares donde reina la desinformación o que han quedado rezagados. De igual forma, es necesario fortalecer la 
democracia basándola en actitudes cívicas y evitar el surgimiento de la etnocracia, donde el voto está motivado según la etnia. Las minorías gagauza, búlgara, ucraniana y rusa en Moldavia deben recibir una atención por parte de los partidos proeuropeos, esto es, proteger sus derechos para que la integración europea también los incluya. La UE puede ayudar ofreciendo un compromiso claro y firme, sobre todo en cuanto a una estrategia de ampliación creíble (Petrov, 2018), premiando la estabilidad política y la democratización del país, a la misma vez que consolidando y haciendo visible su presencia. En concreto, la UE debe exigir reformas en sus negociaciones que luchen contra la corrupción, principal problema en Moldavia y que se traduce en una desafección política, lo que puede suponer un auge de los populismos. Debe aprovechar ser la institución internacional mejor valorada y la única aprobada por la mayoría de la población (63\%), y predicando con el ejemplo de democracia. Por otra parte, no es sugerible una intensificación de los esfuerzos para que Moldavia se plantee su pertenencia a la OTAN ni que esta sea vista como un trampolín para su acceso a la UE: la OTAN tiene el nivel de confianza más bajo en Moldavia (21\%). Al respecto, la misma encuesta señala que se aprecia que un $13 \%$ está más indeciso. Ello sugiere que el discurso político respecto de su pertenencia puede eventualmente comenzar, por lo que la polarización del país puede acrecentarse. En un escenario de polarización y confrontación social, es decir, de un éxito de las estrategias desestabilizadoras en la zona gris, las divisiones internas pueden reabrir el debate sobre la corrección de fronteras (Bernabé-Crespo, 2021a).

A pesar de los crecientes esfuerzos por pertenecer al club europeo, ${ }^{16}$ la membresía se antoja complicada para Moldavia. No solo por la obligación de cumplir los criterios de Copenhague, sino por la particular premisa de ejercer un control efectivo sobre el territorio, sin disputas ni conflictos $^{17}$; el proceso de fatiga de ampliación y las divergentes posturas de los Estados miembros (apoyo más decidido de Rumanía o Alemania; más reticente de Países Bajos o Francia); o las complicadas implicaciones geopolíticas (con respecto a la Federación Rusa) que supondría una nueva incorporación de una ex república soviética. Pese a todo, e incidiendo en esta última consideración, un mero estrechamiento de relaciones con la UE que se conciba como un camino a la futura adhesión puede encontrar rechazo en Transnistria y Gagauzia, y aunque

16 Moldavia, Ucrania y Georgia se han configurado en grupo como el "Trío Asociado" para aunar sus esfuerzos de integración en la Unión Europea (Makszimov, 2021).

17 Por ejemplo, las negociaciones de adhesión de Serbia y Kosovo están supeditadas al llamado "Diálogo de Bruselas" en busca de la normalización de relaciones para resolver disputas territoriales. 
más débilmente, potencialmente en el norte, si las diferencias regionales persisten y no se solucionan los conflictos actuales, transformando la estatalidad en disputada.

\section{Conclusiones}

Moldavia constituye un ejemplo singular para poner en práctica un análisis geográfico que ayude a prevenir situaciones de conflictos de raíz geopolítica. Este tiene en cuenta la identidad (etnia y lengua), los indicadores que permiten caracterizar el nivel de desarrollo de una región (importancia de la agricultura e industria, salarios, tasa de actividad) así como el análisis electoral. La geografía es la ciencia que aporta una visión en conjunto de todos ellos y que permite identificar aquellas áreas netamente diferenciadas de otras, por lo cual, coexisten en un mismo Estado sin apenas tener elementos en común.

Su posición en la frontera exterior de la UE la incluye dentro de un espacio en disputa entre Rusia y la esfera occidental. La persistencia del conflicto todavía congelado de Transnistria y sus lazos con Rusia hacen que Moldavia sea, en buena parte, rehén de este Estado de facto, por lo que se deben reanudar los diálogos para buscar una solución al conflicto. Transnistria no está bajo control de las autoridades moldavas y no existen datos oficiales sobre los indicadores analizados. El resto del territorio se ha analizado y se desprende que existen tres partes diferenciadas, atendiendo a la etnia, lengua, economía y política: el centro del país, más poblado, mayoritariamente rumano, con escasa presencia de minorías étnicas, donde se habla rumano, con una mayor tasa de actividad, más proclive al voto proeuropeo. A pesar de que Moldavia es un país escasamente industrializado y con gran importancia de la agricultura, en el centro del país las extensiones agrícolas son más reducidas y Chisinau sirve como gran centro industrial, lo que supone unos mayores salarios. En el norte del país se cuenta menor población, con una amplia presencia de ucranianos y rusos, y que ha visto mermada gravemente sus efectivos en las últimas décadas, además de una mayor inactividad. La agricultura tiene una destacada importancia y la industria solo es perceptible en Balti, la ciudad que actúa de capital de facto de esta región, que también actúa como feudo tradicional de los partidos prorrusos. En el sur de Moldavia, la composición étnica es más heterogénea y destacan dos grupos: los gagauzos, constituidos en su propia UTA; y los búlgaros en Taraclia. Son distritos eminentemente agrícolas, donde el ruso es preferido por encima del rumano, y donde los proeuropeos apenas cosechan un ínfimo porcentaje del voto. Son distritos herméticos con una fuerte componente identitaria, bien diferenciados del resto del conjunto nacional en la mayoría de los indicadores analizados. 
Estas diferencias internas pueden poner suponer un factor de inestabilidad y potencialmente socavar la estatalidad del país, pudiendo ser aprovechadas por las estrategias de desestabilización propias de la zona gris. Esto reviste especial interés teniendo en cuenta las conexiones que existen entre estas regiones señaladas y dos Estados con una política exterior confrontada como Rusia y Turquía; además de las pretensiones de adhesión de una parte de los moldavos a la UE. Por ello, repensar las políticas interétnicas y profundizar en la protección de las minorías es clave para asegurar una convivencia pacífica y multiétnica. La inversión debe guiarse por la equidad para garantizar una igualdad de oportunidades al desarrollo. Invertir en aquellas regiones que se encuentran en declive constituye una acertada estrategia con el fin de prevenir el descontento social y ayudar a la credibilidad del proyecto europeo. El actual gobierno proeuropeo tiene una oportunidad para preservar la democracia y hacer que la senda europea sea inclusiva y transversal a sus regiones.

El análisis geográfico puede ayudar a identificar las regiones que viven realidades netamente diferentes, y que no poseen elementos que los unan en cuanto a decisiones de carácter geopolítico (adhesión a la UE o acercamiento a Rusia), como pasó en Ucrania donde, provincias que no tenían estatus diferenciado (Donbás) se declararon rebeldes ante los sucesos del Euromaidán. Conocer la realidad geográfica puede servir para evitar el conflicto, para extender el conocimiento de las regiones olvidadas en otros países, y para fortalecer los valores de la identidad europea.

Agradecimientos: Expreso mi agradecimiento a la profesora Fedora Croitor y a las/os evaluadoras/es, cuyas aportaciones han contribuido a la mejora de este manuscrito.

Declaración responsable: El autor declara que no existe ningún conflicto de interés con relación a la publicación de este artículo. 


\section{Bibliografía}

Albentosa, J. A. (2017). Turquía: autoritarismo, islamismo y «neo-otomanismo». Boletín del Instituto Español de Estudios Estratégicos, 7, 1013-1045.

Annual Survey Report (2020). Republic of Moldova. 5th Wave (Spring 2020). OPEN Neighbourhood - Communicating for a stronger partnership: connecting with citizens across the Eastern Neighbourhood. ECORYS. European Union.

Bachtler, J., \& Begg, I. (2018). Beyond Brexit: Reshaping policies for regional development in Europe. Papers in Regional Science, 97(1), 151-170. https://doi.org/10.1111/pirs.12351

Balkan Insight (2020a, October 21). Russia Accuses US of Plotting 'Coloured Revolution' in Moldova. Retrieved from https://balkaninsight.com/2020/10/21/russia-accuses-us-of-plottingcoloured-revolution-in-moldova/

Balkan Insight (2020b, October 30). Moldovans Choose Between East and West at Presidential Elections. Retrieved from hitps://balkaninsight.com/2020/10/30/moldovans-choose-betweeneast-and-west-at-presidential-elections/

BBC (2020, November 16). Moldova election: Pro-EU opposition candidate Maia Sandu wins. Retrieved from https://www.bbc.com/news/av/world-europe-54965755

Bernabé-Crespo, M. B. (2020). Fronteras ocultas en la zona gris europea. Geopolítica(s), Revista de Estudios sobre Espacio y Poder, 11(2), 259-285. https://doi.org/10.5209/geop.64580

Bernabé-Crespo, M. B. (2021a). La partición de Kosovo: ¿̇edibujar fronteras para conseguir la paz? Documents d'Anàlisi Geogràfica, 67(2), 189-218. hitps://doi.org/10.5565/rev/dag.668

Bernabé-Crespo, M. B. (2021b). ¿Un Euromaidán en Belarús? La Revolución Blanca de 2020 en el contexto de la zona gris europea. In XXVII Congreso de la Asociación Española de Geografía, "Geografía, cambio global y sostenibilidad". AGE: Universidad de La Laguna.

Bieber, F., \& Keil, S. (2009). Power-sharing revisited: lessons learned in the Balkans. Review of Central and East European Law, 34, 337360. https://doi.org/10.1163/092598809X12474728805778

Browning, C. S. (2018). Geostrategies, geopolitics and ontological security in the Eastern neighbourhood: The European Union and the 'new Cold War'. Political Geography, 62, 106115. https://doi.org/10.1016/i.polgeo.2017.10.009 
Bürkner, H. J. (2020). Europeanisation versus Euroscepticism: Do borders matter? Geopolitics, 25(3), 545-566. https://doi.org/10.1080/14650045.2020.1723964

Cadier, D. (2018). The geopoliticisation of the EU's Eastern partnership. Geopolitics, 11(2), 71 99. https://doi.org/10.1080/14650045.2018.1477754

Cairo, H. (1993). Elementos para una geopolítica crítica: tradición y cambio en una disciplina maldita. Ería, 32, 195-213.

Cairo, H. (2002). La ampliación oriental de la Unión Europea: Identidades y discursos geopolíticos. Revista Universitaria Europea, 3, 33-44.

Cairo, H., \& Lois, M. D. (2014). Geografía política de las disputas de fronteras: cambios y continuidades en los discursos geopolíticos en América Latina (1990-2013). Cuadernos de Geografía: Revista Colombiana de Geografía, 23(2), 45-

67. https://doi.org/10.15446/rcdg.v23n2.39578

Caspersen, N., \& Stansfield, G. (Eds.) (2011). Unrecognized states in the international system. London: Routledge.

Chinn, J. \& Roper, S. D. (1998). Territorial autonomy in Gagauzia. Nationalities Papers, 26(1), 87101. https://doi.org/10.1080/00905999808408552

Cojocaru, N. (2006). Nationalism and identity in Transnistria. Innovation: The European Journal of Social Science Research, 19(3-4), 261-272. https://doi.org/10.1080/13511610601029813

Colom, G. (2020). Anatomía de la desinformación rusa. Historia y comunicación social 25(2), 473-480. http://dx.doi.org/10.5209/hics.63373

Cordesman, A. H., \& Hwang, G. (2020). Chronology of possible Russian Gray area and hybrid warfare operations. Working Draft: July 2, 2020. Center for Strategic International Studies.

Daily Sabah (2019, December 30). Economic ties between Turkey, Moldova to grow stronger. Retrieved from: https://www.dailysabah.com/economy/2019/12/30/economic-ties-betweenturkey-moldova-to-grow-stronger

Daily Sabah (2020, September 7). Turkey to continue to aid Moldova and Gagauzia, Turkish envoy says. Retrieved from https://www. dailysabah.com/politics/diplomacy/turkey-to-continueto-aid-moldova-and-gagauzia-turkish-envoy-says 
David, M., \& Romanova, T. (2015). Modernisation in EU-Russian relations: Past, present, and future. European Politics and Society, 16(1), 10. https://doi.org/10.1080/15705854.2014.965895

Dawson, J. I. (1997). Ethnicity, ideology and geopolitics in Crimea. Communist and PostCommunist Studies, 30(4), 427-444. https://doi.org/10.1016/S0967-067X(97)00013-5

Del Sarto, R. A., \& Schumacher, T. (2005). From EMP to ENP: What's at stake with the European neighbourhood policy towards the Southern Mediterranean? European Foreign Affairs Review, 10(1), 17-38.

Dijkstra, L., Poelman, H., \& Rodríguez-Pose, A. (2020). The geography of EU discontent. Regional Studies, 54(6), 737-753. https://doi.org/10.1080/00343404.2019.1654603

El Mundo (2020, December 1). Maia Sandu, presidenta electa de Moldavia: "Una Moldavia estable conviene a Rusia y a la UE". Retrieved from https://www.elmundo.es/internacional/2020/12/01/5fc5448ffc6c83306a8b45c7.html

Englund, S. H. (2020). A dangerous middle-ground: terrorists, counter-terrorists, and gray-zone conflict. Global Affairs, 58(4-5), 389-404. https://doi.org/10.1080/23340460.2019.1711438

Fidrmuc, J., Hulényi, M., \& Tunali, Ç. B. (2019). Can money buy EU love? European Journal of Political Economy, 60, 101804. https://doi.org/10.1016/j.ejpoleco.2019.07.002

Financial Times (2020, December 23). Moldova's PM quits ahead of pro-western president's inauguration. Retrieved from https://www.ft.com/content/fd1c7f4b-37fc-4586-9db9$\underline{d d 4 a 7 d 40435 e ? \text { shareType }=\text { nongift }}$

Forsberg, T., \& Mäkinen, S. (2019). Russian discourse on borders and territorial questions Crimea as a watershed? Russian Politics, 4, 211-241. https://doi.org/10.1163/2451-8921$\underline{00402004}$

Foxall, A. (2009). A "new Cold War": Re-drawing the MAP/map of Europe. Political Geography, 28(6), 329-331. https://doi.org/10.1016/j.polgeo.2009.07.003

Ganson, B., \& Wennmann, A. (2012). Operationalising Conflict Prevention as Strong, Resilient Systems: Approaches, Evidence, Action Points. Geneva: Peacebuilding Platform (Paper n³).

Giband, D., \& Vicente, J. (2018). Los espacios transfronterizos europeos: ¿uun objeto geográfico de difícil definición? Una aproximación desde la perspectiva de los soft spaces. Documents d'Anàlisi Geogràfica, 64(3), 421-441. https://doi.org/10.5565/rev/dag.520 
González, M. (2017). El proceso secesionista en Transnistria: implicaciones regionales e internacionales. Documento de Opinión, 79, 543-563. Instituto Español de Estudios Estratégicos. Retrieved from http://www.ieee.es/Galerias/fichero/docs_opinion/2017/DIEEEO792017_Transnistria_MiriamGlezFco.pdf

Goodwin, M. J., \& Heath, O. (2016). The 2016 referendum, Brexit and the left behind: An aggregate-level analysis of the result. Political Quarterly, 87(3), 323332. https://doi.org/10.1111/1467-923X.12285

Gordon, I. R. (2018). In what sense left behind by globalisation? Looking for a less reductionist geography of the populist surge in Europe. Cambridge Journal of Regions, Economy and Society, 17(1), 95-113. https://doi.org/10.1093/cjres/rsx028

Gray, C. (1977). The Geopolitics of the Nuclear Era. New York: Crane Russak.

Groza, I. (2019). Moldova: Renewed hope after a string of setbacks. In S. Secrieru \& S. Saari, The Eastern Partnership: A decade on (pp. 42-56). European Union Institute for Security Studies.

Groza, I., Jopp, M., Kulminski, V., Pistrinciuc, V., Popov, A., Popescu, A., \& Rusu, I. (2018). Strengthening Social Cohesion and a Common Identity in the Republic of Moldova. German Federal Foreign Office, Institute Pentru Initiative Strategice, Institut für Europäische Politik \& Institutul de Politici și Reforme Europene.

Hamm, M. F. (1998). Kishinev: The character and development of a Tsarist frontier town. Nationalities Papers, 26 (1), 19-37. https://doi.org/10.1080/00905999808408548

Haukkala, H. (2015). From cooperative to contested Europe? The conflict in Ukraine as a culmination of a long-term crisis in EU-Russia relations. Journal of Contemporary European Studies 23(1), 25-40. https://doi.org/10.1080/14782804.2014.1001822

Hobolt, S. B. (2016). The Brexit vote: a divided nation, a divided continent. Journal of European Public Policy, 23(9), 1259-1277. https://doi.org/10.1080/13501763.2016.1225785

Hoffman, F. G. (2016). The contemporary spectrum of conflict: protracted, gray zone, ambiguous, and hybrid models of war. In 2016 Index of U.S. Military Strength (pp. 25-36). The Heritage Foundation.

lammarino, S., Rodríguez-Pose, A., \& Storper, M. (2019). Regional inequality in Europe: evidence, theory and policy implications. Journal of Economic Geography, 19(2), 273298. https://doi.org/10.1093/jeg/lby021 
Jordán, J. (2018). El conflicto internacional en la zona gris: una propuesta teórica desde la perspectiva del realismo ofensivo. Revista Española de Ciencia Polífica, 48, 129151. https://doi.org/10.21308/recp.48.05

Jordán, J. (2019). Rusia y el conflicto en la zona gris en la región báltica. Temas profesionales, 913-930. Retrieved from https://www.ugr.es/ jjordan/zona-gris-rusia-baltico.pdf

Kapusta, P. (2015). The Gray Zone. Special Warfare Magazine, 19-25. Retrieved from https://www.soc.mil/SWCS/SWmag/archive/SW2804/GrayZone.pdf

Kaufman, S. J., \& Bowers, S. R. (1998). Transnational dimensions of the Transnistrian conflict. Nationalities Papers, 26(1), 129-146. https://doi.org/10.1080/00905999808408554

King, C. (1994). Moldavian identity and the politics of pan-Romanianism. Slavic Review, 53(2), 345-368. Retrieved from: http://www.jstor.org/stable/2501297? origin=JSTOR-pdf

King, C. (1998). Ethnicity and institutional reform: The dynamics of 'indigenization' in the Moldovan ASSR. Nationalities Papers, 26(1). https://doi.org/10.1080/00905999808408550

Kolossov, V. \& O'Loughlin, J. (1998). Pseudo-states as harbingers of a new geopolitics: The example of the trans-dniester Moldovan republic (TMR). Geopolitics, 3(1), 151176. https://doi.org/10.1080/14650049808407612

Kolsto, P. (1995). Russians in the Former Soviet Republics. Bloomington: Indiana University Press.

Kolsto, P. (2006). The sustainability and future of unrecognized quasi-states. Journal of Peace Research, 43(6), 723-740. hitps://doi.org/10.1177\%2F0022343306068102

Kolsto, P., \& Malgin, A. (1998). The Transnistrian republic: A case of politicized regionalism. Nationalities Papers, 26(1), 103-127. https://doi.org/10.1080/00905999808408553

Kommersant (2009, February 27). "Восточное партнерство" напоминает кольцо вокруг России". Retrieved from https://www.kommersant.ru/doc/1126593

Lanoszka, A. (2016). Russian hybrid warfare and extended deterrence in Eastern Europe. International Affairs, 92(1), 175-195. https://doi.org/10.1111/1468-2346.12509

Mackinlay, J., \& Cross, P. (2003). Regional Peacekeepers: The Paradox of Russian Peacekeeping. United Nations University Press.

Makszimov, V. (2021). Georgia, Moldova, Ukraine formalise their higher EU ambition. Euractiv, 18 May 2021. Retrieved from https://www.euractiv.com/section/easterneurope/news/georgia-moldova-ukraine-formalise-their-higher-eu-ambition/ 
Marcu, S. (2004). La región geopolítica del Mar Negro: entre la integración y la fragmentación. Boletín de la Asociación de Geógrafos Españoles, 38, 199-224. Retrieved from https://bage.age-geografia.es/ojs/index.php/bage/article/view/489

Marcu, S. (2009). The geopolitics of the eastern border of the European Union: The case of Romania-Moldova-Ukraine. Geopolitics, 409432. https://doi.org/10.1080/14650040802693796

Marcu, S. (2011). Pax Russica: ambigüedad geopolítica de las tensiones y conflictos en el espacio de la antigua Unión Soviética. Investigaciones Geográficas, 55, 91 111. https://doi.org/10.14198/INGEO2011.55.06

Marcu, S. (2021). Geopolítica de Rusia y Europa Oriental. Madrid: Editorial Síntesis.

Martin, R., Tyler, P., Storper, M., Evenhuis, E., \& Glasmeier, A. (2018). Globalization at a critical conjuncture? Cambridge Journal of Regions, Economy and Society, 11(1), 316. https://doi.org/10.1093/cjres/rsy002

Nogué, J., \& Vicente, J. (2001). Geopolítica, identidad y globalización. Barcelona: Ariel.

O'Loughlin, J., Toal, G., \& Kolosov, V. (2017). Who identifies with the Russian World: Geopolitical attitudes in Southeastern Ukraine, Crimea, Abkhazia, South Ossetia and Transnistria. $\begin{array}{llll}\text { Eurasian Geography } & \text { 745- }\end{array}$ 778. https://doi.org/10.1080/15387216.2017.1295275

Ojala, M., \& Pantti, M. (2017). Naturalising the new cold war: The geopolitics of framing the Ukrainian conflict in four European newspapers. Global Media and Communication, 13(1), 4156. https://doi.org/10.1177\%2F1742766517694472

Papadimitriou, D., \& Petrov, P. (2012). Whose rule, whose law? Contested statehood, external leverage and the European Union's rule of law mission in Kosovo. Journal of Common Market Studies 50(5), 746-763. https://doi.org/10.1111/j.1468-5965.2012.02257.x

Petrov, R. (2018). EU common values in the EU-Ukraine Association Agreement: Anchor to democracy? Baltic Journal of European Studies 8(1), 49-62. https://doi.org/10.1515/bjes-20180004.

Pikulicka-Wilczewska, A., \& Sakwa, R. (Eds.) (2015). Ukraine and Russia: People, Politics, Propaganda and Perspectives. Bristol: E-International Relations. 
Plaza, J. I. (2011). Conflictos geopolíticos y tensiones en el mundo actual. Investigaciones Geográficas, 55, 7-15. https://doi.org/10.14198/INGEO2011.55.01

Radaelli, C. M. (2004). Europeanisation: Solution or Problem? European Integration Online Papers, 8(16), 1-26. Retrieved from http://www.eiop.or.at/eiop/pdf/2004-016.pdf

Raik, K. (2019). The Ukraine Crisis as a Conflict over Europe's Political, Economic and Security Order. Geopolitics, 24(1), 51-70. https://doi.org/10.1080/14650045.2017.1414046

Rodríguez-Pose, A. (2018). The revenge of the places that don't matter (and what to do about it). Cambridge Journal of Regions, Economy and Society, 11(1), 189209. https://doi.org/10.1093/cjres/rsx024

Rodríguez-Pose, A., \& Dijkstra, L. (2020). Does cohesion policy reduce EU discontent and Euroscepticism? (Working Paper 04/2020. Directorate-General for Regional and Urban Policy). European Commission. Retrieved from https://ec.europa.eu/regional_policy/en/information/publications/workingpapers/2020/does-cohesion-policy-reduce-eu-discontent-and-euroscepticism

Rodrik, D. (2018). Populism and the economics of globalization. Journal of International Business Policy, 1(1-2), 12-33. Retrieved from https://link.springer.com/article/10.1057/s42214-018$\underline{0001-4}$

Sánchez, W. A. (2009). The 'frozen' Southeast: How the Moldova-Transnistria question has become European geo-security issue. The Journal of Slavic Military Studies, 22(2), 153176. https://doi.org/10.1080/13518040902917917

Sasse, G. (2002). Conflict-prevention in a transition state: The Crimean issue in post-Soviet Ukraine. Nationalism and Ethnic Politics, 8(2), 26. https://doi.org/10.1080/13537110208428659

Schadlow, N. (2014, August 18). Peace and War: The Space Between. In War on the Rocks. Retrieved from https://warontherocks.com/2014/08/peace-and-war-the-space-between/

Schraff, D. (2019). Regional redistribution and Eurosceptic voting. Journal of European Public Policy, 26(1), 83-105. https://doi.org/10.1080/13501763.2017.1394901

Starr, H. (2013). On geopolitics: Spaces and places. International Studies Quarterly, 57(3), 433439. Retrieved from https://www.jstor.org/stable/24017914 
Svarin, D. (2016). The construction of 'geopolitical spaces' in Russian foreign policy discourse before and after the Ukraine crisis. Journal of Eurasian Studies, 7, 129140. https://doi.org/10.1016/i.euras.2015.11.002

Tass (2020, November 30). Песков: изменение статус-кво в Приднестровье может привести к серьезной дестабилизации. Retrieved from https://tass.ru/politika/10129237

The Moscow Times (2020, December 1). Pull Russian Troops Out of Moldova, New President Says. Retrieved from https://www.themoscowtimes.com/2020/11/30/pull-russian-troops-out-ofmoldova-new-president-says-a72184

The Guardian (2014, August 15). Moldova fights back against Russia's food bans. Retrieved from https://www.theguardian.com/world/2014/aug/15/moldova-fights-back-russia-food-bans The Washington Post (2020, November 23). Moldova's new president is likely to seek closer ties with Europe. Russia won't be pleased. In Washington Post. Retrieved from https://www.washingtonpost.com/politics/2020/11/23/moldovas-new-president-is-likelyseek-closer-ties-with-europe-russia-wont-be-pleased/?fbclid=IwAR3jHWr23KVGtA4-1Dhs3uu6c1Cfn62TTHrAZOMdT4EekktyLHHSmevDG8

Trenin, D. (2016). Should we fear Russia? Cambridge: Polity Press.

Tsygankov, A. (2015). Vladimir Putin's last stand: The sources of Russia's Ukraine policy. PostSoviet Affairs, 37(4), 279-303. https://doi.org/10.1080/1060586X.2015.1005903

UN (2018, June 22). General Assembly Adopts Texts Urging Troop Withdraw from Republic of Moldova, Strengthening Cooperation in Central Asia. Retrieved from https://www.un.org/press/en/2018/ga12030.doc.htm

Walters, W. (2004). The frontiers of the European union: A geostrategic perspective. Geopolitics, 9(3), 674-698. https://doi.org/10.1080/14650040490478738

Wilson, A. (2020, November 19). Separate ways: Contrasting elections in Georgia and Moldova. European Council on Foreign Relations. Retrieved from https://ecfr.eu/article/seperate-wayscontrasting-elections-in-georgia-and-moldova/

Wirtz, J. J. (2017). Life in the "gray zone": observations for contemporary strategists. Defense and Security Analysis, 33(2), 106-114.

Wolff, S., \& Yakinthou, C. (Eds.) (2012). Conflict Management in Divided Societies: Theories and Practice. New York: Routledge. 
Служба внешней разведки Российской Федерации (2020, October 19). О вмешательстве сша в выборы в Молдавии. Retrieved from: http://svr.gov.ru/smi/2020/10/o-vmeshatelstve-ssha-vvybory-v-moldavii-

htm?fbclid=IwAROmVQqGWZzid1QIElY4e0a1SzQ7CDbm58rLXI|JGY9mkkHwVkRh8JN06GE 